\title{
Seasonal dynamics of the copepod community in a tropical monsoonal estuary and the role of sex ratio in their abundance pattern
}

\author{
G. Vineetha*, N. V. Madhu, K. K. Kusum and P. M. Sooria
}

\begin{abstract}
Background: As salinity is considered the prime "ecological master factor" governing the zooplankton distribution and abundance in estuaries, a spatio-temporal interactive approach was followed to assess whether the responses of the estuarine copepod community towards the salinity are always direct with a strong positive affinity or whether there exist any complexities in their interrelationship. The study, also for the first time, addressed the role of sex ratio in governing the abundance and the population structure of copepods in the tropical monsoonal estuarine system.
\end{abstract}

Results: The ecological scenario in the Cochin estuary revealed that irrespective of the season, higher zooplankton abundance occurred in the mesohaline zone (MSZ; salinity 5-18) of the estuary, despite the pronounced spatial shift of the MSZ from the lower reaches of the estuary to upstream locations, in conjunction with the varying seasonal fluvial influx and marine water intrusion. In the case of the sex ratio of copepods, the seasonal scenario revealed that the dominant copepods had a lower sex ratio during the period of higher abundance, and a negative relation was observed between the abundance and the sex ratio of copepod species during most of the seasons.

Conclusions: The preponderance of the mesohaline and euryhaline species of the copepod community formed the key contributing factor towards the maintenance of higher abundance in the MSZ of the estuary. The bias in the sex ratio towards females favored higher reproductive output, resulting in the higher abundance during the favorable pre-monsoon period.

Keywords: Zooplankton; Monsoonal estuary; Mesohaline; Copepod; Sex ratio

\section{Background}

Estuaries, the confluence of marine and limnetic ecosystems, are considered one of the most productive natural habitats on earth (Alongi 1998). Though representing only $6 \%$ of the total coastal zone area, these aquatic ecosystems play a pivotal role in the global carbon balance (Smith and Hollibaugh 1993) and nutrient recycling (Fisher et al. 1982) and serve as a conducive breeding and nursing environment for many commercially important shell and fin fishes (Haedrich 1983).The high physicochemical variability associated with estuarine ecosystems often affects the abundance and distribution of the estuarine organisms immensely, leading to prominent spatial and temporal

\footnotetext{
* Correspondence: vineetha.varada@gmail.com

CSIR-National Institute of Oceanography, Regional Centre, Dr. Salim Ali Road, Kochi, India
}

\section{勿

heterogeneity in their abundance and community structure (Collins and Williams 1981; Madhupratap 1987; Laprise and Dodson 1994). Of the multitude of environmental variables, salinity is often considered the prime "ecological master" (Kinne 1966), evoking pronounced spatio-temporal variability in the estuarine zooplankton dynamics, as salinity experiences wide gradients in the spatial distribution, with high-salinity zones in the inlet locations to limnetic environments in the upstream regions, which in turn undergo prominent temporal variability associated with seasonal fluvial influxes. Hence, the interrelation between salinity and zooplankton and also the mode of salinity regulation on zooplankton dynamics have been central aims for many plankton ecological studies in estuaries worldwide (Baretta and Malschaert 1988; Kimmerer 2002). 
The Cochin estuary (CE), heavily influenced by the Indian summer monsoon, differs from all other estuaries by its unsteadiness in salinity characteristics and also in its total runoff, which is many times higher than the estuarine volume (Vijith et al. 2009; Revichandran et al. 2012) (June-September), resulting in a possible washout during the monsoon period. This uniqueness in the estuarine features of the CE thus demands a comprehensive study for identifying the regulatory mechanisms underlying the seasonal variability in the abundance, distribution, and population maintenance of the endemic copepoda community of this estuarine ecosystem. In the CE, as salinity is taken as the major limiting factor influencing the zooplankton standing stock and abundance (Madhupratap 1987; Madhu et al. 2007), we aimed to evaluate whether the responses of the estuarine copepods are always direct with a strong affinity towards salinity or whether the estuarine copepods exhibit wide complexities in their responses to the variability in salinity characteristics.

As copepods form the predominant zooplankton taxon in terms of both abundance and diversity and since they form a critical component of the estuarine trophic ecology (Baretta and Malschaert 1988; Soetaert and Rijswijk 1993; Froneman 2004), the variability in their population dynamics, in conjunction with the prevailing environmental conditions, is very much decisive in the better understanding of the seasonal dynamics of the zooplankton community in the estuarine ecosystem. Copepods, being dioecious organisms with sexually dimorphic males and females, each exhibiting prominent sexspecific differences in their physiological longevity (Rodríguez-Graña et al. 2010), growth, and mortality rates (Ohman and Hsieh 2008), the responses of individuals belonging to varied sexes to environmental variability are expected to play a crucial role in the population dynamics of the estuarine copepod community. Though there are ample studies regarding biasness from the Fischerian 1:1 sex ratio in the natural population of various copepod species (Moraitou-Apostolopaulou 1972; Hirst et al. 2010) and also on the factors responsible for the biasness in sex ratio (Gusmão et al. 2013), the evaluation of the influence that sex ratio has on the abundance pattern and population dynamics of the estuarine copepod community is mostly overlooked. In this context, we aimed to study the variability in sex ratio of the dominant species among the copepod community in the $\mathrm{CE}$ and to assess the determining role that sex ratio has on their seasonal community structure and population maintenance in a tropical monsoonal estuarine system.

\section{Methods}

Study area

$\mathrm{CE}$ is an oxbow-shaped monsoonal estuarine system located along the southwest coast of India (Gupta et al.
2009) (Fig. 1). This microtidal estuary ( 1 m) (Qasim 2003), with a surface area of $231 \mathrm{~km}^{2}$, makes perennial connections to the Arabian Sea through two inlets: one at Cochin (width $450 \mathrm{~m}$ ) and the other at Azhikode (width $250 \mathrm{~m}$ ). Heavily influenced by the Indian summer monsoon, the annual precipitation of the CE is around $320 \mathrm{~cm}$, of which around $75 \%$ occurs during the summer monsoon period (June-September) (Qasim 2003). The estuary receives an influx of about $22,000 \times$ $10^{6} \mathrm{~m}^{3}$ of freshets annually (Revichandran et al. 2012) from seven perennial rivers-Periyar, Chalakudy, Pamba, Muvattupuzha, Manimala, Meenachil, and Achancoil-and their tributaries. The seasonal asymmetry in the balance between the fluvial runoff associated with the Indian summer monsoon and the tidal incursion from the Arabian Sea often evokes intense heterogeneity in the spatio-temporal characteristics of the CE.

\section{Sampling}

Monthly sampling was carried out at eight locations along the salinity gradient, covering the entire CE (Fig. 1), from June 2008 to May 2009. Stations 1 and 2 were the two inlets (Azhikode and Cochin, respectively) at the lower reaches of the estuary. Stations 3, 4, and 5 were the nearinlet locations to the middle reaches of the estuary, and stations 6,7 , and 8 were in the southern upper reaches of the estuary. An SBE Seabird 19 plus CTD was deployed at every station location to measure the surface water temperature and salinity. Water samples were collected from the surface $(0.5 \mathrm{~m})$ using Niskin samplers for the estimation of salinity, $\mathrm{pH}$, dissolved oxygen (DO), suspended particulate matter (SPM), and chlorophyll $a$. Surface salinity values obtained through the CTD were further counterchecked by using a digital salinometer for better precision of the data (DIGI-AUTO, 3G Tsurumi Seiki, Japan, accuracy \pm 0.001 ), and $\mathrm{pH}$ was estimated using a $\mathrm{pH}$ meter (ELICO LI610, accuracy \pm 0.01 ). The estimation of DO was carried out following Winkler's method (Grasshoff 1983). SPM was determined by filtering $250 \mathrm{ml}$ of water sample onto pre-weighed Millipore filter paper $\left(0.45-\mu \mathrm{m}\right.$ pore size) and drying the residue at $80{ }^{\circ} \mathrm{C}$. The weight of the particles collected on the filter paper was estimated gravimetrically following the standard procedure (APHA 2005). Chlorophyll $a$ was measured using a flourometer (Trilogy, Turner Designs, USA) after filtering $500 \mathrm{ml}$ water on $\mathrm{GF} / \mathrm{F}$ filter papers (pore size $0.7 \mu \mathrm{m}$ ), followed by overnight extraction in $10 \mathrm{ml} 90 \%$ acetone (Strickland and Parsons 1972). For phytoplankton species identification, $500 \mathrm{ml}$ of water sample from the surface $(0.5 \mathrm{~m})$ was fixed in $1 \%$ Lugol's iodine and enumerated under an inverted microscope (OLYMPUS, CK-30, magnification $\times 100$ ) in a Sedgewick-Rafter counting chamber following standard protocols (Tomas 1997). Zooplankton 


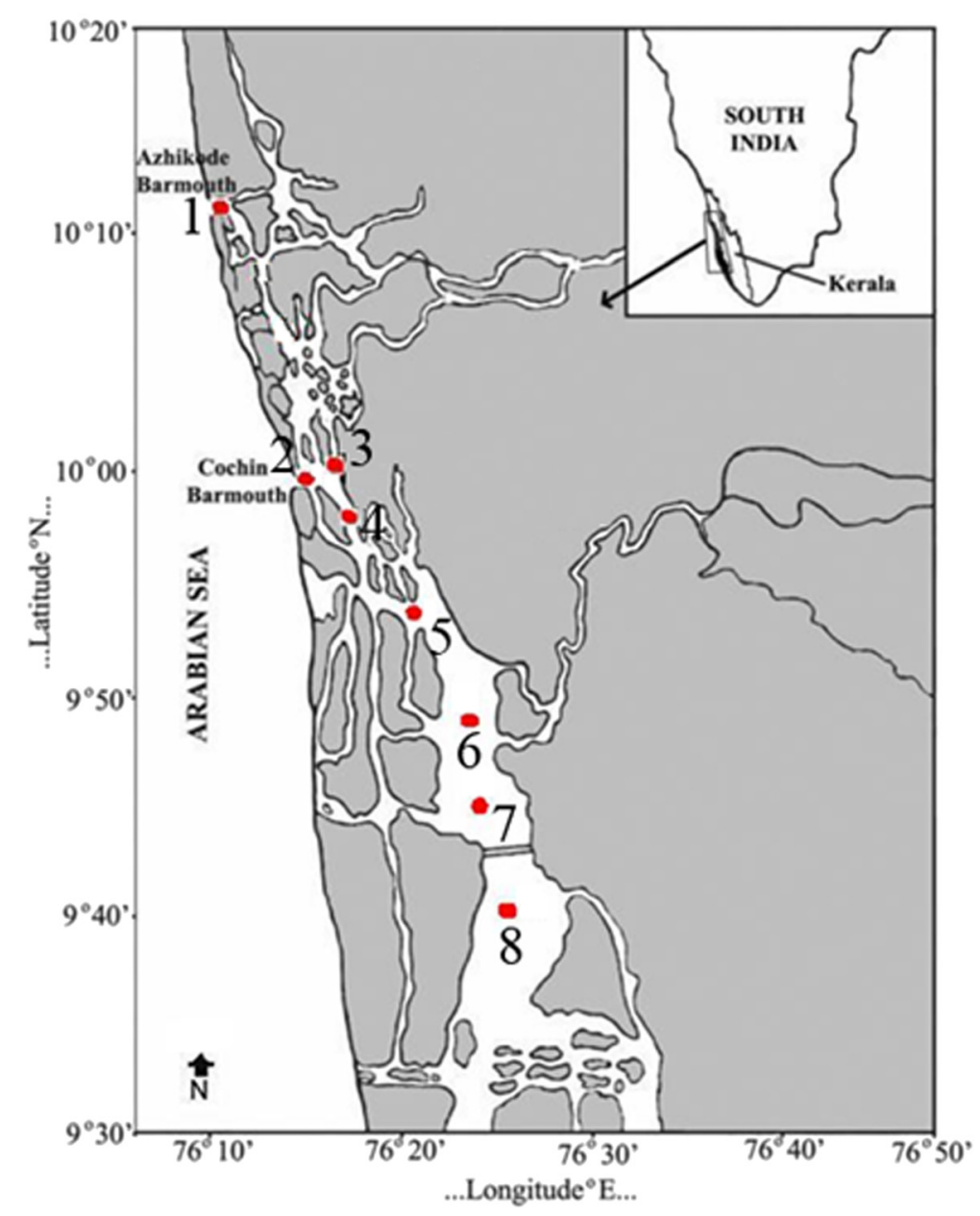

Fig. 1 Sampling locations in Cochin estuary

samples were collected using a Working Party net-2 (mesh size $200 \mu \mathrm{m}$ ) with a mouth area of $0.28 \mathrm{~m}^{2}$. The net was hauled horizontally just below the surface for $10 \mathrm{~min}$ with an approximate speed of 1 knot to minimize net avoidance by the larger zooplankton. A digital flow meter (Hydro Bios, Model-438110) was attached across the mouth of the net to estimate the amount of water filtered. Zooplankton biomass was estimated by the displacement volume method after removing large detrital particles and was preserved in $4 \%$ formaldehyde solution (Harris et al. 2000). Zooplankton groups were sorted, counted, and identified to the lowest possible taxon, and the abundance was expressed as individuals per cubic meter (ind. $\mathrm{m}^{-3}$ ). Copepod species level identification was carried out following the identification keys of Sewell (1999), Kasturirangan (1963), and Wellershaus (1969). For calculating the sex ratio (male:female) of the dominant copepod species, the identification of their sex was carried out mostly on the $\mathrm{C} 5$ and adult stages, since sexes in copepod can only be morphologically distinguished in the late stages of development (Gusmão et al. 2013).

\section{Data analysis}

To check whether a significant variation exists between the seasonal values of both abiotic and biotic parameters, one-way analysis of variance (ANOVA) was performed. Before the analysis, the D'Agostino and Pearson omnibus normality test was carried out to check their normality in distribution, and based on the result, parametric or non-parametric ANOVA was performed for the variables with two-tailed $P$ values and $95 \%$ confidence intervals.

The dominant species of both the phytoplankton and copepod communities are expected to play a vital role in the ecological process of the estuarine system because of their higher numerical abundance. Hence, for identifying the dominant species in the estuarine system, along with their abundance, the spatial frequency of occurrence was 
also considered and calculated according to Yang et al. (1999) as:

$$
Y_{i}=\left(N_{i} / N\right) \times f_{i}
$$

where $Y_{i}$ is the dominance of species $i$

$N_{i}$ is the number of individuals of species

$N$ is the number of individuals of all species at all locations

$f_{i}$ is the frequency of locations at which species $i$ occur.

The species with a $Y$ value of $\geq 0.02$ were considered the dominant species (Yang et al. 1999; Lee et al. 2009).

While assessing the seasonal dynamics of the copepod community, the characterizing species of each season were identified following the similarity percentage (SIMPER) routine implemented in PRIMER (Clarke and Gorley 2006) to get the best-suited representative of a particular season. These species deal with good intragroup similarity and less standard deviation. The characterizing species among the phytoplankton for each season were also identified following the same procedure.

Redundancy analysis (RDA) was performed on the physicochemical variables and chlorophyll $a$ and for both the characterizing and dominant species of copepods during each season for a better elucidation of the relationship existing between them (Van den Wollenberg 1977). The advantage of RDA is that it allows one to obtain a simultaneous representation of the observations of the response variables (species) and the explanatory variables (physicochemical variables and chlorophyll $a$ ) in two or three dimensions, and the position of the variables in the triplot helps in visualizing their interrelationships. Further, for a detailed understanding of the interrelation existing among the phytoplankton and the copepod community of the CE, RDA was carried out between the characterizing and dominant species along different seasons using the statistical software, CANOCO 4.5.

To check the similarity in the distribution of copepod species, agglomerative hierarchical cluster analysis was performed based on the Bray-Curtis similarity during each season, and a similarity profile (SIMPROF) test was done further to identify the significantly correlated species. Further, to find out the similarity between station locations, non-metric multidimensional scaling (NMDS) was performed based on the similarity in the distribution of different copepod species, using PRIMER (Clarke and Gorley 2006).

To analyze the seasonal variability in the assemblages of the copepod community, the diversity indices, such as species diversity $\left(H^{\prime}\right)$ and species evenness $\left(J^{\prime}\right)$, were calculated using PRIMER (Clarke and Warwick 2001).To identify the interrelation between the sex ratio and the abundance of the dominant copepod species, Pearson's correlation analysis was performed followed by a linear regression analysis based on the monthly data of the sex ratio and abundance during each season. Considering the wide variations in the abundance, $\log _{e}$-transformed abundance value was used for the analysis. As the dominant copepod species were not observed at few station locations during some months, the number of samples $(n)$ varied along seasons. To check whether the regression lines (slopes) are significantly different from zero, a one-sample $t$ test was also carried out. In estuaries, along with the sex ratio, as the freshwater gradient along stations also may influence the zooplankton distribution and abundance, the effect of the freshwater content (FWC) on distribution of the dominant species was also assessed by plotting it against the residuals extracted from the regression plot of the sex ratio and abundance. The amount of FWC along each location was calculated as follows:

$$
\begin{aligned}
& \text { FWC at station } i(\%) \\
& \qquad=\frac{\text { Salinity of the open ocean-Salinity of the station } i}{\text { Salinity of the open ocean }} \times 100
\end{aligned}
$$

\section{Results}

\section{Physicochemical variables}

Among the environmental variables, the spatiotemporal distribution in the water temperature did not show much variation during the sampling periods (Fig. 2a), whereas salinity exhibited marked seasonal variation in the estuary $(P<0.05)$ (Fig. $2 \mathrm{~b})$. Seasonal averages showed relatively higher salinity during the premonsoon (average (av.) 19.2 \pm 6.8 ) when compared to the monsoon (av. 5.4 \pm 9.7 ) and post-monsoon seasons (av. 16.1 \pm 11.8 ). During the pre-monsoon season, salinity was relatively high in all station locations, and a mesohaline zone with salinity $5-18$ was observed in the stations located at the upper reaches of the estuary (stations 6, 7, and 8) (Fig. 2b). With the onset of the monsoon season, a sudden drop in salinity was observed throughout the estuary, and it was $<1$ at the stations in the southern upper reaches of the estuary (stations 6, 7, and 8). During this period, relatively higher salinity was observed, mainly in the inlet stations, among which the maximum value was recorded at station 1 (Fig. 2b). With the post-monsoon season, salinity progressively increased in the estuary, and the mesohaline zone prevailed at the middle reaches of the estuary, mostly at station 5 . Stations $1-4$ exhibited relatively higher salinity, whereas a low-salinity environment (salinity $<5$ ) prevailed at the upstream locations of the estuarine region (stations 6, 7, and 8). Though the dissolved oxygen (DO) showed higher values during the monsoon season compared to both the pre- and post- 

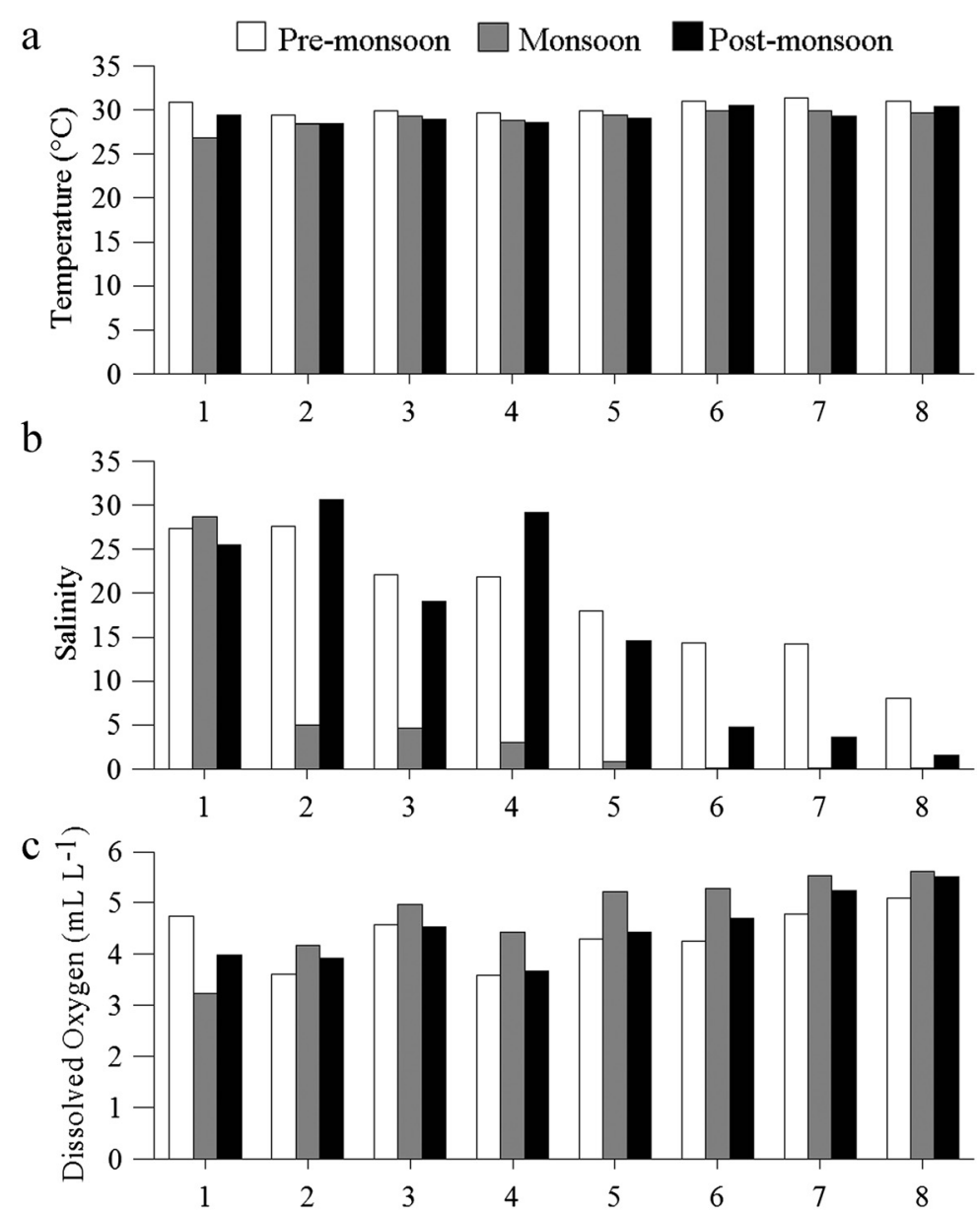

d
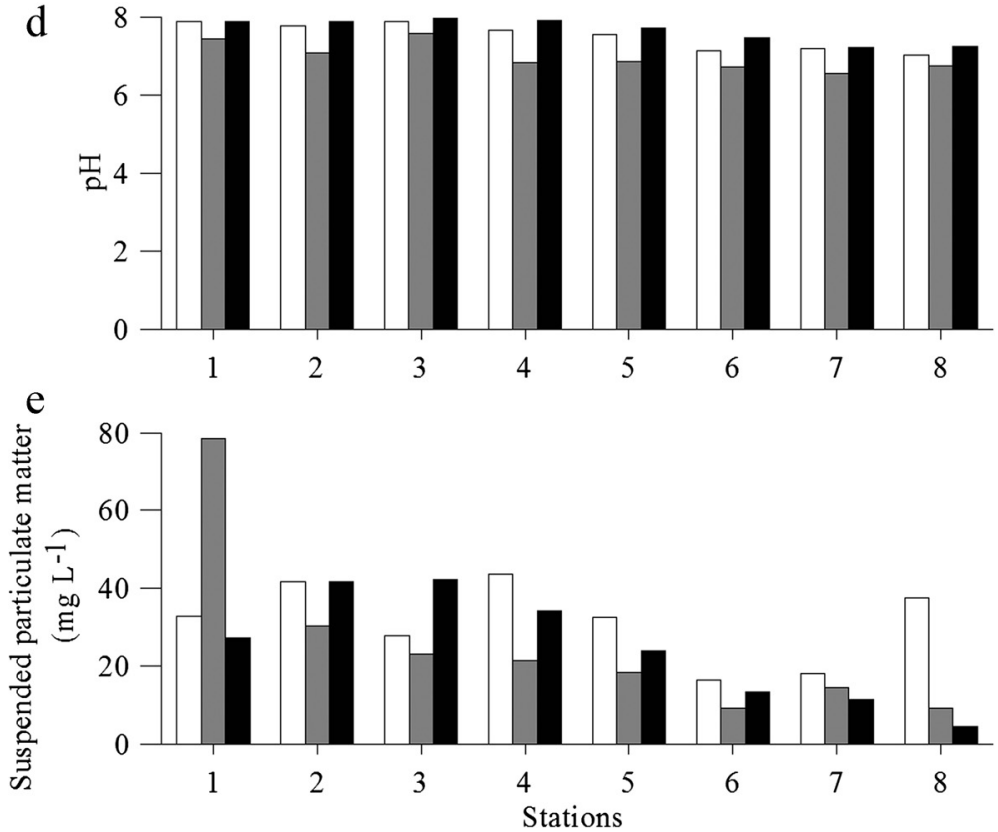

Fig. 2 Distribution of the physicochemical variables a temperature, $\mathbf{b}$ salinity, $\mathbf{c}$ dissolved oxygen, $\mathbf{d} \mathrm{pH}$, and $\mathbf{e}$ suspended particulate matter along the sampling locations in each season 
monsoon periods at all station locations except station 1 (Fig. 2c), the difference was not statistically significant $(P>0.05)$. The $\mathrm{pH}$ values at all station locations were relatively lower during the monsoon period compared to the other two seasons (Fig. 2d) and exhibited a prominent seasonal variation $(P<0.05)$, which was opposite to the trend observed in the DO distribution. Though SPM varied seasonally throughout the station locations (Fig. 2e), the difference was statistically insignificant $(P>0.05)$.

\section{Chlorophyll $a$ and phytoplankton composition}

The seasonal scenario in the chlorophyll $a$ distribution during the study period revealed relatively higher values during the pre-monsoon $\left(5.6-31.2 \mathrm{mg} \mathrm{m}^{-3}\right.$, av. $10.9 \pm 8.4 \mathrm{mg}^{-3}$ ) compared to the monsoon $\left(4.8-17.6 \mathrm{mg} \mathrm{m}^{-3}\right.$, av. $8.7 \pm$ $4.1 \mathrm{mg} \mathrm{m}^{-3}$ ) and post-monsoon seasons (2.7-16.8 $\mathrm{mg} \mathrm{m}^{-3}$, av. $6.9 \pm 4.5 \mathrm{mg} \mathrm{m}^{-3}$ ) (Fig. 3a), but this difference was statistically insignificant $(P>0.05)$. As the phytoplankton community composition and their relative contribution exhibited both spatial and temporal variabilities, to assess

a

b
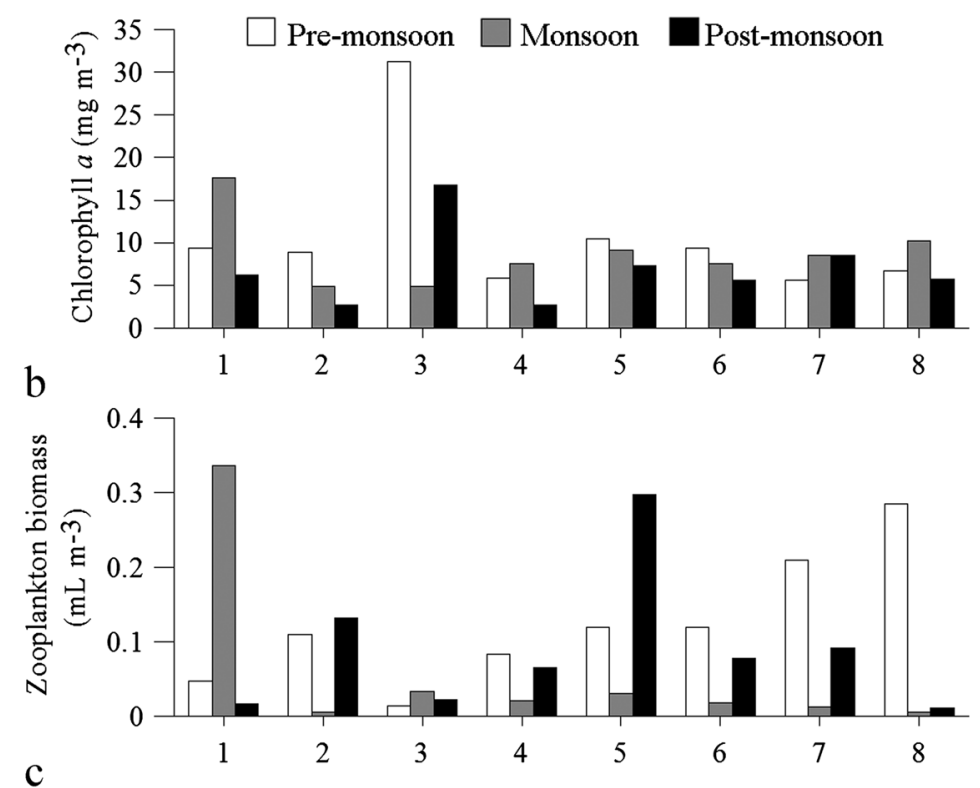

C
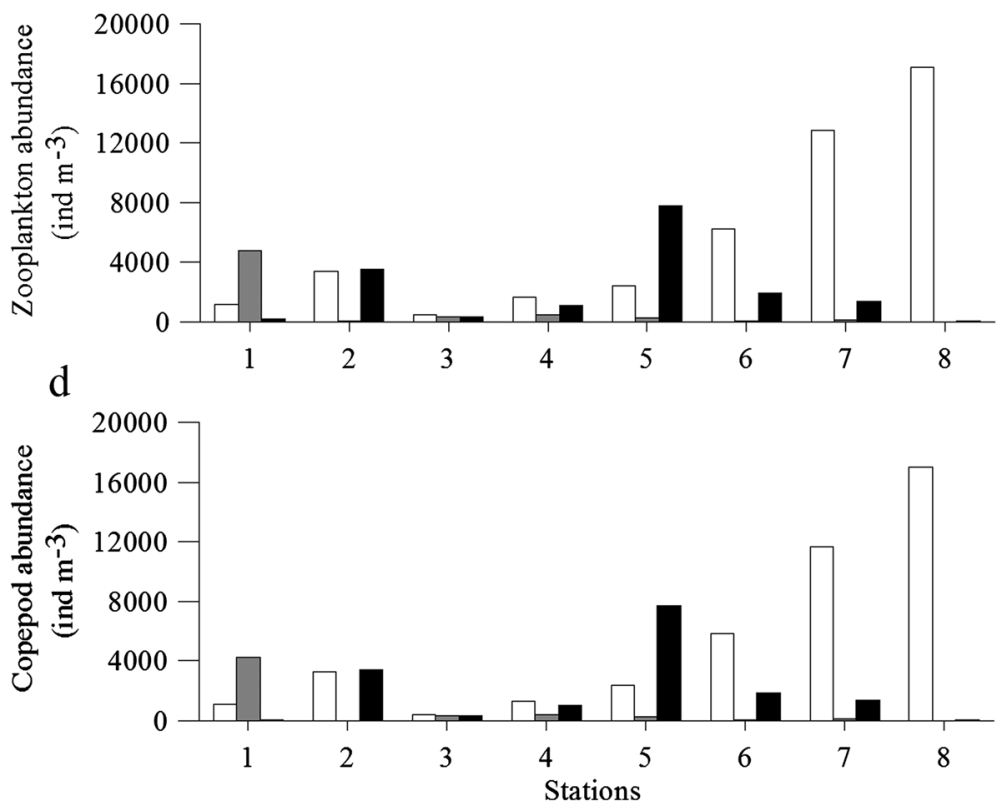

Fig. 3 Distribution of the biotic parameters a chlorophyll $a$, b zooplankton biomass, c zooplankton abundance, and $\mathbf{d}$ copepod abundance along the sampling locations in each season 
their influence on the copepod species, the dominant and characterizing species of phytoplankton were identified (for details, see Additional file 1). In general, diatoms and dinoflagellates contributed a relatively major share among the phytoplankton community during each season.

\section{Zooplankton biomass, abundance, and composition}

Pronounced spatio-temporal variation in the zooplankton biomass and abundance was observed in the estuary during the study period (Fig. 3b, c). Both biomass and abundance were higher during the pre-monsoon when compared to the monsoon and post-monsoon periods (Fig. 3b, c), and the seasonal variation was significantly different $(P<0.05)$. During the pre-monsoon season, relatively higher biomass and abundance were observed at the mesohaline zone located in the upper reaches of the estuary (stations 6, 7, and 8) than in other locations. During the monsoon season, a sharp decline in zooplankton biomass and abundance $\left(<0.1 \mathrm{ml} \mathrm{m}^{-3}\right)$ occurred in all stations throughout the estuary except at station $1\left(0.34 \mathrm{ml} \mathrm{m}^{-3}\right)$. With the post-monsoon season, a slight increase in the zooplankton biomass and abundance was observed in most of the stations, and the maximum value was observed at the mesohaline location at station $5\left(0.30 \mathrm{ml} \mathrm{m}^{-3}\right)$ (Fig. 3b, c).

The zooplankton community of the CE was represented by 16 groups of holoplankton and seven groups of meroplankton (Table 1). Irrespective of seasons, copepoda formed the most dominant zooplankton taxon, and though there was a significant variation in their seasonal abundance $(P<0.05)$, similar to zooplankton distribution, relatively higher abundance of copepoda was observed in the mesohaline zones of the estuary (Fig. 3d). During the pre-monsoon season, copepoda contributed to $94.9 \%$ of the total population, and with the onset of the monsoon season and a subsequent drop in the salinity, the holoplankton composition changed drastically throughout the estuary. Though copepods formed the dominant representative, during the monsoon season, their percentage contribution (87.8\%) decreased considerably, and cladocera (9.8\%) formed the next abundant group. Though the holoplanktonic taxa, like mysida and amphipoda, were present throughout the seasons, their abundance varied greatly between the seasons. The holoplanktonic groups, like thaliacea and pteropoda, with comparatively high-salinity preferences, were observed only during the pre-monsoon and post-monsoon periods, respectively (Table 1). Among the meroplankton, decapod larvae, gastropod larvae, and lamellibranch larvae dominated, with relatively higher abundance during the pre-monsoon period (Table 1).
Table 1 Zooplankton composition and abundance (ind. $\mathrm{m}^{-3}$ ) during each season

\begin{tabular}{|c|c|c|c|}
\hline Group & PRM & MS & PM \\
\hline \multicolumn{4}{|l|}{ Holoplankton } \\
\hline Hydromedusae & 5 & 0.034 & 0.004 \\
\hline Siphonophore & 0.001 & - & 0.1 \\
\hline Ctenophore & 0.018 & 0.474 & - \\
\hline Polycheata & 0.084 & 0.031 & 0.025 \\
\hline Chaetognatha & 2 & 7 & 4 \\
\hline Copepoda & 5369 & 673 & 2152 \\
\hline Ostracoda & - & 0.004 & - \\
\hline Cladocera & 0.039 & 75 & 0.287 \\
\hline Mysid & - & 0.014 & 0.0157 \\
\hline Isopoda & 0.001 & 0.002 & - \\
\hline Amphipoda & 0.157 & 0.054 & 0.528 \\
\hline Stomatopoda & 0.001 & - & 0.005 \\
\hline Luciferiidae & 15 & 2 & 1 \\
\hline Thaliacea & - & 0.011 & - \\
\hline Appendicularia & - & 0.069 & 0.14 \\
\hline Pteropoda & - & - & 0.003 \\
\hline Copepoda nauplii & 13 & - & 12 \\
\hline \multicolumn{4}{|l|}{ Meroplankton } \\
\hline Polychaete larvae & 0.015 & 0.132 & - \\
\hline Decapod larvae & 57 & 3.5 & 6 \\
\hline Cirriped larvae & 2 & - & 0.112 \\
\hline Gastropod larvae & 162 & 0.438 & 6 \\
\hline Lamellibranch larvae & 24 & 0.648 & 1.469 \\
\hline Fish eggs & 5 & 0.186 & 7.5 \\
\hline Fish larvae & 1 & 4 & 1 \\
\hline
\end{tabular}

PRM pre-monsoon, $M S$ monsoon, $P M$ post-monsoon

\section{Copepod composition and abundance}

The copepod abundance during the pre-monsoon period (av. $5369 \pm 5954$ ind. $\mathrm{m}^{-3}$ ) was markedly higher than in the monsoon (av. $673 \pm 1433$ ind $\mathrm{m}^{-3}$ ) and postmonsoon periods (av. $2152 \pm 2566$ ind. $\mathrm{m}^{-3}$ ) (Fig. 3d). Copepod, the dominant taxon among the zooplankton community in the $\mathrm{CE}$, was represented by 31 species of calanoids, 3 species of cyclopoids, 2 species of poecilostomatoids, and 1 species of harpacticoid (Table 2). Among the calanoids, the family Acartiidae and Paracalanidae dominated throughout the study period, of which the most abundant species were Bestiolina similis, Acartia plumosa, Acartiella gravelyi, Acartiella keralensis, and Acartia centrura. High-saline copepods, like Labidocera pectinata, Acartia erythraea, Acartia spinicauda, and Subeucalanus subcrassus, were observed in varying densities, mostly in or near the two inlets. Oithona brevicornis, belonging to the family Oithonidae, showed higher abundance among the cyclopoids. The 
Table 2 List of the copepod species along different seasons in Cochin estuary

\begin{tabular}{|c|c|c|c|}
\hline Copepoda species & Pre-monsoon & Monsoon & Post-monsoon \\
\hline Acartia centrura Giesbrecht, 1889 & $* * * *$ & $* * *$ & $* * *$ \\
\hline Acartia spinicauda Giesbrecht, 1889 & $* * *$ & $* *$ & $* * *$ \\
\hline Acartia erythraea Giesbrecht, 1889 & * & - & * \\
\hline Acartia plumosa Scott T., 1894 & $* * * * *$ & $* * *$ & $* * * * *$ \\
\hline Acartia bowmani Abraham, 1976 & $* *$ & $* *$ & - \\
\hline Acartiella gravelyi Sewell, 1919 & $* * *$ & $* * *$ & ** \\
\hline Acartiella keralensis Wellershaus 1969 & $* * * *$ & $* *$ & $* * *$ \\
\hline Paracalanus aculeatus Giesbrecht, 1888 & $* * *$ & - & $* * *$ \\
\hline Bestiolina similis Sewell, 1914 & $* * * * *$ & $* * * *$ & $* * * *$ \\
\hline Acrocalanus monachus Giesbrecht, 1888 & - & - & $* *$ \\
\hline Pseudodiaptomus annandalei Sewell, 1919 & $* * *$ & $* *$ & $* * *$ \\
\hline Pseudodiaptomus serricaudatus Scott T., 1894 & ** & * & $* * *$ \\
\hline Pseudodiaptomus malayalus Wellershaus 1969 & * & $* *$ & $* * *$ \\
\hline Pseudodiaptomus mertoni Früchtl, 1924 & - & $* *$ & - \\
\hline Heliodiaptomus cinctus Gurney, 1907 & - & ** & - \\
\hline Allodiaptomus mirabilipes Kiefer, 1936 & - & $* *$ & - \\
\hline Subeucalanus subcrassus Giesbrecht, 1888 & $* * *$ & * & $* * *$ \\
\hline Subeucalanus crassus Giesbrecht, 1888 & * & $* *$ & $* *$ \\
\hline Undinula vulgaris Dana, 1849 & $* *$ & * & $* * *$ \\
\hline Canthocalanus pauper Giesbrecht, 1888 & * & * & $* *$ \\
\hline Centropages alcocki Sewell, 1912 & $* *$ & $* * *$ & $* * *$ \\
\hline Centropages furcatus Dana, 1849 & $* * *$ & * & $* * *$ \\
\hline Centropages tenuiremis Thompson \& Scott, 1903 & $* *$ & - & - \\
\hline Centropages trispinosus Sewell, 1914 & $* *$ & $* * *$ & $* *$ \\
\hline Centropages calaninus Dana, 1849 & $* *$ & * & ** \\
\hline Centropages orsiini Giesbrecht, 1889 & - & - & $* *$ \\
\hline Candacia bradyi Scott A., 1902 & - & - & $* *$ \\
\hline Labidocera pectinata Thompson \& Scott, 1903 & ** & - & $* *$ \\
\hline Labidocera acuta Dana, 1849 & ** & - & - \\
\hline Temora turbinata Dana, 1849 & - & - & ** \\
\hline Tortanus forcipatus Giesbrecht, 1889 & - & - & * \\
\hline Oithona brevicornis Giesbrecht, 1891 & $* * *$ & $* * *$ & $* * *$ \\
\hline Oithona rigida Giesbrecht, 1896 & - & * & - \\
\hline Oncaea venusta Philippi, 1843 & $*$ & - & * \\
\hline Mesocyclops sps & * & $* *$ & $* *$ \\
\hline Euterpina acutifrons Dana, 1847 & * & - & $* *$ \\
\hline Onychocorycaeus catus Dahl, 1894 & * & - & $* *$ \\
\hline
\end{tabular}

*indicates abundance $<1$ ind. $\mathrm{m}^{-3}$; **indicates $1-10$ ind. $\mathrm{m}^{-3}$; ***indicates $10-100$ ind. $\mathrm{m}^{-3}$; ****indicates $100-1000$ ind. $\mathrm{m}^{-3}$; ****indicates $>1000$ ind. $\mathrm{m}^{-3}$

poecilostomatoids, Oncaea venusta and Onychocorycaeus catus, and the harpacticoid, Euterpina acutifrons, were also observed in varying densities during the preand post-monsoon periods (Table 2).

During the pre-monsoon season, a total of 28 species were observed throughout the estuary, and the higher copepod abundance at the mesohaline zone at stations
6,7 , and 8 was mostly contributed by the medium-saline (salinity preference $\sim 10-20)$ A. plumosa, Ac. keralensis, and euryhaline $B$. similis. Based on the dominancy analysis, these three were found as the dominant species of this period. The SIMPER analysis revealed a total of 8 species as the characterizing species of the pre-monsoon period, which are listed in Table 3. With the onset of the 
Table 3 Result of the SIMPER analysis exhibiting the characteristic species of each season

\begin{tabular}{|c|c|c|c|c|c|}
\hline Species & Av. Abund & Av. Sim & $\mathrm{Sim} / \mathrm{SD}$ & Contrib \% & Cum. \% \\
\hline \multicolumn{6}{|l|}{ Pre-monsoon } \\
\hline Bestiolina similis & 5.85 & 16.66 & 4.25 & 36.59 & 36.59 \\
\hline Acartia plumosa & 4.61 & 11.17 & 1.52 & 24.53 & 61.11 \\
\hline Acartiella keralensis & 2.94 & 3.76 & 0.48 & 8.26 & 69.37 \\
\hline Acartia centrura & 1.87 & 3.14 & 0.71 & 6.91 & 76.28 \\
\hline Oithona brevicornis & 1.54 & 2.86 & 0.7 & 6.29 & 82.56 \\
\hline Pseudodiaptomus annandalei & 1.07 & 1.54 & 0.67 & 3.38 & 85.94 \\
\hline Labidocera pectinata & 0.99 & 1.45 & 0.71 & 3.19 & 89.13 \\
\hline Centropages alcocki & 0.88 & 1.01 & 0.5 & 2.22 & 91.35 \\
\hline \multicolumn{6}{|l|}{ Monsoon } \\
\hline Acartia plumosa & 2.2 & 7.92 & 2.93 & 16.44 & 16.44 \\
\hline Bestiolina similis & 2.39 & 7.43 & 3.29 & 15.43 & 31.87 \\
\hline Acartiella gravelyi & 1.66 & 6.78 & 2.01 & 14.07 & 45.94 \\
\hline Mesocyclops sps & 1.08 & 4.92 & 1.44 & 10.22 & 56.16 \\
\hline Allodiaptomus mirabilipes & 1.09 & 4.19 & 1.41 & 8.69 & 64.85 \\
\hline Oithona brevicornis & 1.45 & 3.74 & 2.47 & 7.76 & 72.61 \\
\hline Pseudodiaptomus malayalus & 0.9 & 2.98 & 0.94 & 6.18 & 78.79 \\
\hline Heliodiaptomus cinctus & 0.99 & 2.85 & 1.26 & 5.91 & 84.71 \\
\hline Pseudodiaptomus annandalei & 1.01 & 2.6 & 0.92 & 5.41 & 90.11 \\
\hline \multicolumn{6}{|l|}{ Post-monsoon } \\
\hline Bestiolina similis & 4.23 & 10.2 & 3.99 & 24.1 & 24.1 \\
\hline Acartia plumosa & 3.48 & 6.45 & 1.42 & 15.24 & 39.34 \\
\hline Oithona brevicornis & 2.37 & 5.01 & 1.63 & 11.85 & 51.19 \\
\hline Acartia centrura & 1.95 & 2.98 & 1.02 & 7.03 & 58.23 \\
\hline Pseudodiaptomus annandalei & 1.26 & 2.49 & 1.5 & 5.89 & 64.12 \\
\hline Acartiella keralensis & 1.45 & 1.86 & 0.58 & 4.39 & 68.51 \\
\hline Pseudodiaptomus serricaudatus & 1.3 & 1.78 & 1.02 & 4.21 & 72.72 \\
\hline Centropages alcocki & 1.17 & 1.23 & 0.71 & 2.9 & 75.62 \\
\hline Pseudodiaptomus malayalus & 1.07 & 1.12 & 0.5 & 2.66 & 78.28 \\
\hline Centropages furcatus & 1.3 & 1.11 & 0.51 & 2.61 & 80.89 \\
\hline Subeucalanus subcrassus & 1.07 & 0.95 & 0.51 & 2.25 & 83.14 \\
\hline Centropages calaninus & 0.75 & 0.95 & 0.51 & 2.25 & 85.38 \\
\hline Acartiella gravelyi & 0.83 & 0.94 & 0.46 & 2.23 & 87.61 \\
\hline Undinula vulgaris & 1.09 & 0.91 & 0.51 & 2.15 & 89.76 \\
\hline Centropages trispinosus & 0.95 & 0.84 & 0.51 & 1.99 & 91.75 \\
\hline
\end{tabular}

The analysis was performed based on the fourth root transformed abundance data of copepod species. As for a good charactering species, the average similarity for a particular taxa within a group should be greater than its intragroup standard deviation (SD) by a factor of at least one, they were marked with bold letters Av average, Abund abundance, Sim similarity, Contrib contribution, Cum. cumulative

monsoon season, copepod diversity dropped throughout the estuary, and the community was represented by about 24 species of copepods. During this period, maximum density (4198 ind. $\mathrm{m}^{-3}$ ) and species diversity were observed at station 1, the Azhikode inlet. A. plumosa, A. centrura, and $B$. similis and the low-saline (salinity preference <10) Ac. gravelyi were found as the dominant species during this period. Another low-saline species,
Heliodiaptomus cinctus (av. 5 ind. $\mathrm{m}^{-3}$ ), was also observed but with varying density. A total of 9 species were found as the characterizing species, and among them, 4 species were observed to be common during both the pre-monsoon and monsoon periods (Table 3). During the post-monsoon season, species diversity among copepods was high and was represented by a total of 30 species and was dominated by A. plumosa, B. similis, and $A$. 
centrura. The maximum abundance of copepods was observed at the mesohaline zone at station 5 (7700 ind. $\mathrm{m}^{-3}$ ). Among the 15 species found as the characterizing species during this period, A. plumosa, B. similis, Pseudodiaptomus annandalei, and O. brevicornis, were found as common during all three seasons (Table 3).

\section{Multivariate analysis}

The RDA triplot helped in unfolding the preferred abiotic environment for both the characterizing and dominant species of the copepods in each season and also indicated the influence of chlorophyll $a$ on them (Fig. 4). During the premonsoon season, when a high-salinity environment prevailed in a major part of the estuary, the dominant species exhibited a negative relation with salinity and a positive relation with temperature and DO, whereas several characterizing species showed close affinity to SPM but had no proper trend with salinity (Fig. 4a). During the low-salinity period of the monsoon season, few dominant and characterizing species showed positive affinity with salinity, SPM, and $\mathrm{pH}$ (Fig. 4b). During the post-monsoon period, the dominant species showed neither positive nor negative affinity with salinity (Fig. 4c). During most of the study period (except monsoon), the majority of the dominant and characterizing species did not show any definite relationship with chlorophyll $a$ (Fig. 4). Hence, a detailed study on the interrelation among the species of the copepods and phytoplankton (both characterizing and dominant species) was performed for each season, and the triplot in the RDA was helpful in both visualizing all the data points plotted in the coordinate system and identifying the interrelationship among them (Fig. 5). Irrespective of season, A. plumosa and B. similis, which were dominant throughout the study period, showed a preference for the autotrophic dinoflagellate species

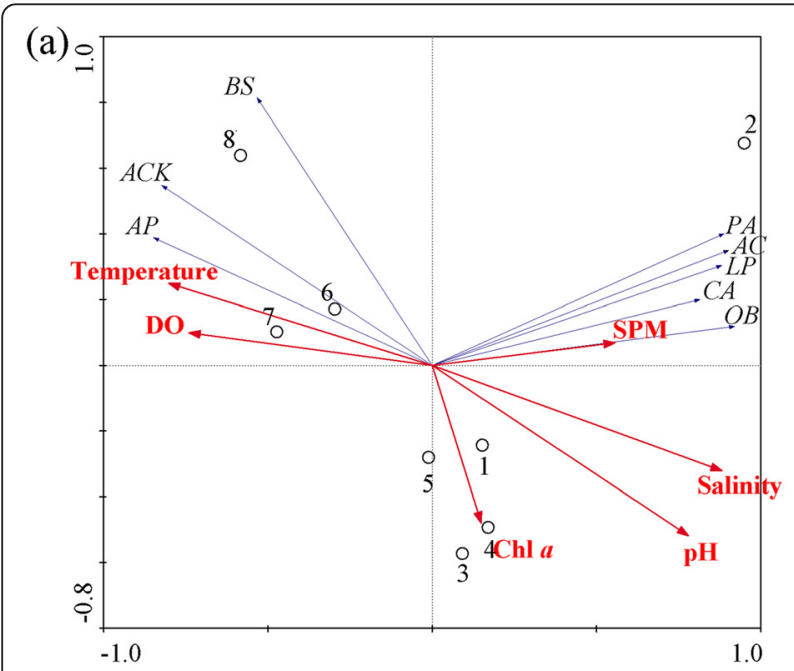

(b)

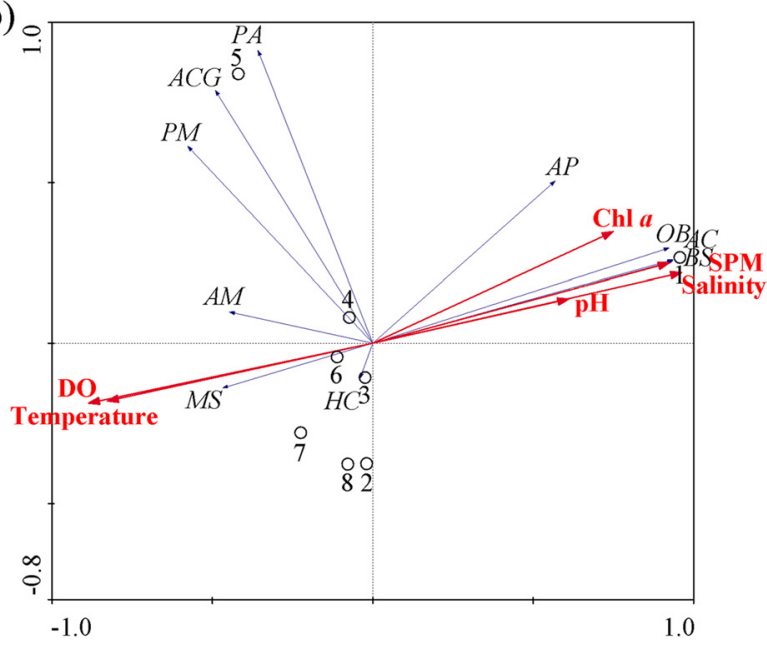

(c)

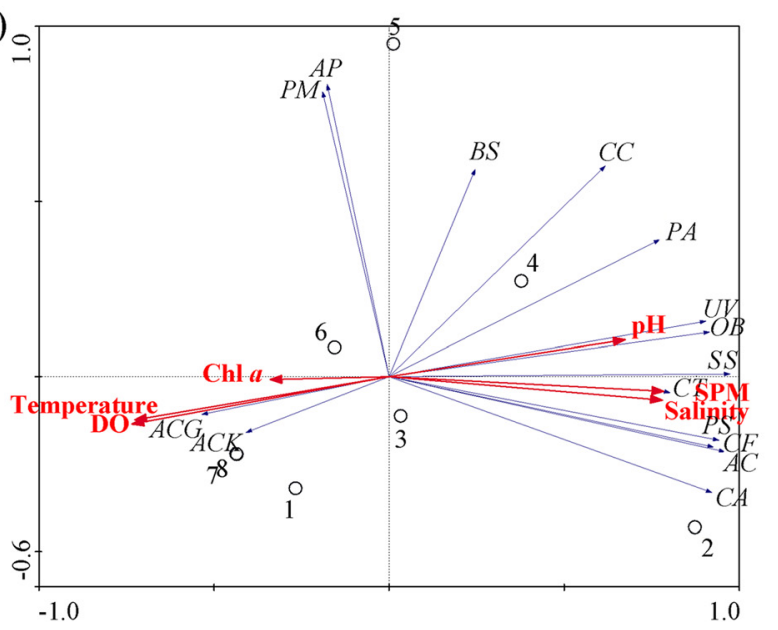

AC - Acartia centrura ACK - Acartiella keralensis $A C G$ - Acartiella gravelyi AM - Allodiaptomus mirabilipes AP - Acartia plumosa $B S$ - Bestiolina similis $C A$ - Centropages alcocki $C C$ - Centropages calaninus $\mathrm{CF}$ - Centropages furcatus CT - Centropages trispinosus $H C$ - Heliodiaptomus cinctus LP - Labidocera pectinata MS - Mesocyclops sps.

Fig. 4 The redundancy analysis triplot displaying the ecological relationship between physicochemical variables, chlorophyll $a$, and dominant and characterizing copepod species during the $\mathbf{a}$ pre-monsoon, $\mathbf{b}$ monsoon, and $\mathbf{c}$ post-monsoon periods. The direction of an arrow dictates the direction of increase of that particular variable on spatially assembled sampling locations 


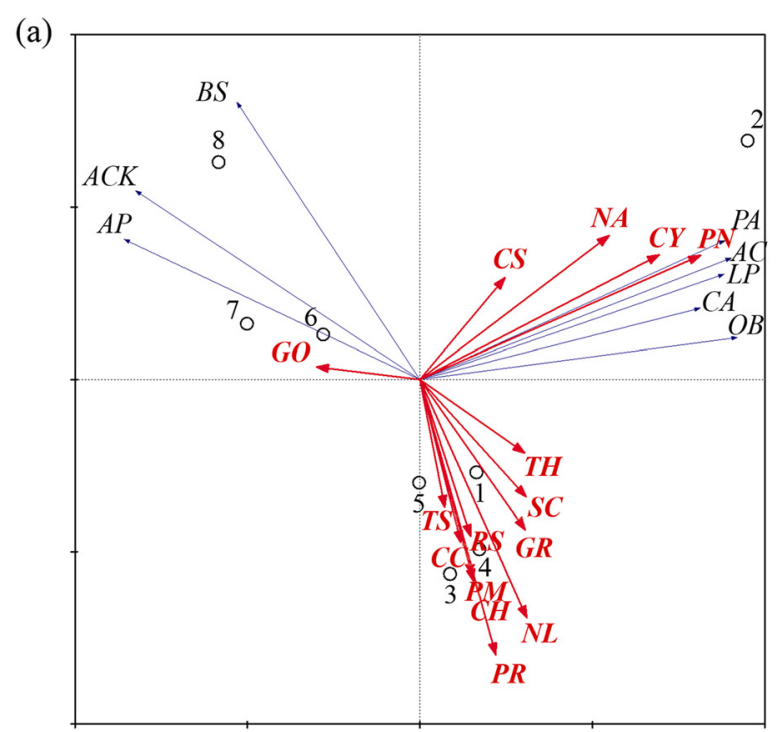

(c)

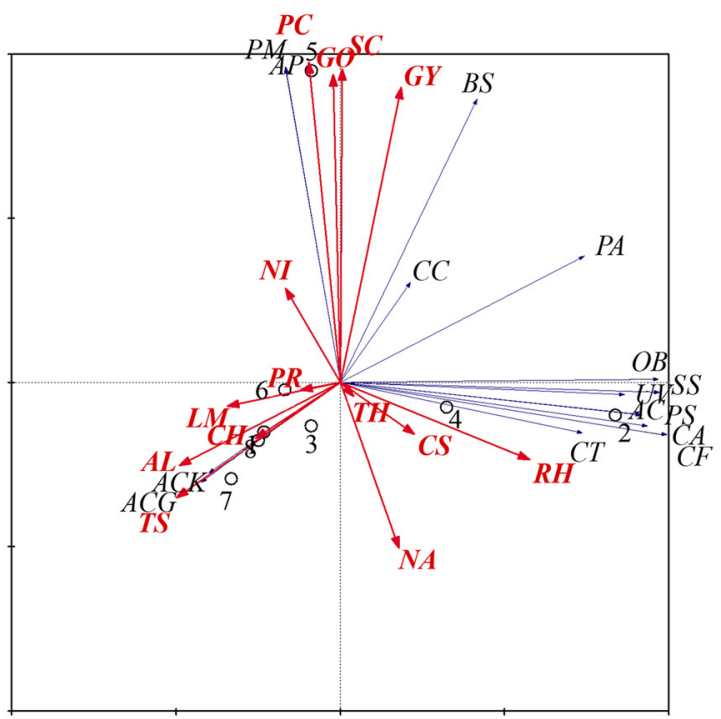

(b)

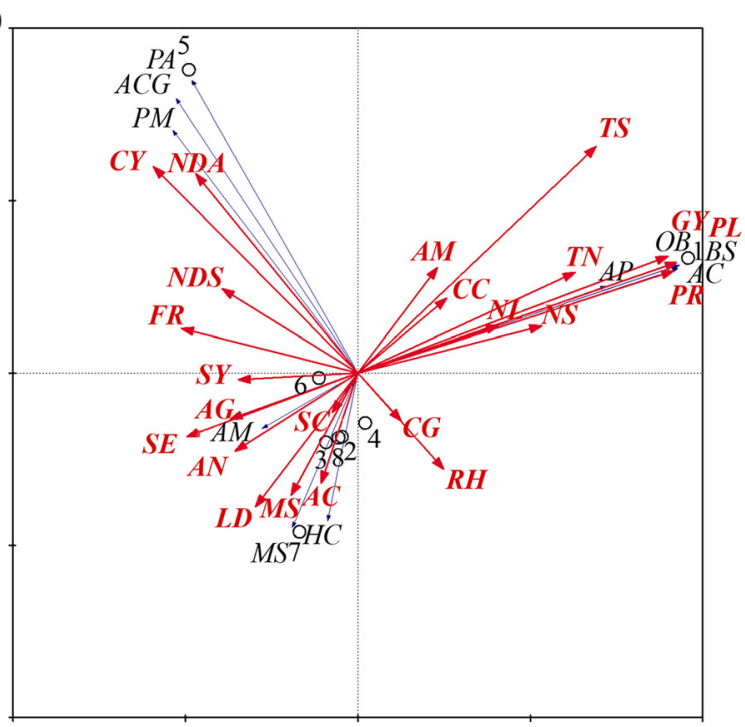

Phytoplankton species

$A C$ - Actinastrum sps.

$A G$ - Agmenellum sps.

$A L-$ Alexandrium sps.

$A M$ - Amphiprora sps.

AN - Anacystis sps.

$\mathrm{CH}$ - Chaetoceros sps.

$C G$ - Coscinodiscus gigas

CS - Coscinodiscus sps.

CY - Cyclotella sps.

$C C$ - Cylindrotheca closterium

FR - Fragilaria sps.

GO - Gonyaulax sps.

GR - Grammatophora sps.

GY - Gymnodinium sps.

LD - Leptocylindrus danicus

LM - Leptocylindrus minimus

MS - Melosira sulcata

NDA - Navicula directa
NDS - Navicula distans

NA - Navicula sps.

$N L$ - Nitzschia longissima

NS - Nitzschia seriata

$P N$ - Pleurosigma normanii

$P L$ - Prorocentrum lima

$P M$ - Prorocentrum micans

$P C$ - Prorocentrum sps.

$P R$ - Protoperidinium sps.

$R S$ - Rhizosolenia setigera

$R H$ - Rhizosolenia sps.

$S E$ - Scenedesmus sps.

$S C$ - Skeletonema costatum

$S Y$ - Synedra sps.

$T N$ - Thalassionema nitzschioides

TS - Thalassiosira subtilis

TH - Thalassiosira sps.

\section{Copepod species}

$A C$ - Acartia centrura
ACK - Acartiella keralensis
ACG - Acartiella gravelyi
AM - Allodiaptomus mirabilipes
AP - Acartia plumosa

$B S$ - Bestiolina similis

$C A$ - Centropages alcocki

$C C$ - Centropages calaninus

$\mathrm{CF}$ - Centropages furcatus

CT-Centropages trispinosus
$H C$ - Heliodiaptomus cinctus

LP - Labidocera pectinata

MS - Mesocyclops sps.

$O B$ - Oithona brevicornis

$P A$ - Pseudodiaptomus annandalei
PM - Pseudodiaptomus malayalus PS - Pseudodiaptomus serricaudatus SS - Subeucalanus subcrassus $U V$ - Undinula vulgaris

Fig. 5 The RDA triplot showing interrelation between copepod and phytoplankton species (dominant and characterizing species) during the a pre-monsoon, $\mathbf{b}$ monsoon, and $\mathbf{c}$ post-monsoon periods. The red color indicates the phytoplankton species, and the black color indicates the copepod species

compared to the diatoms. The preference of the low-saline species of copepods (H. cinctus, Allodiaptomus mirabilipes, Mesocyclops sps) for the phytoplankton species of the lowsaline environment (Anacystis sps, Actinastrum sps, Synedra sps, Scenedesmus sps, Melosira sulcata) was evident during the monsoon season (Fig. 5).
Cluster analysis and non-metric multidimensional scaling

The dendogram of the copepod species, based on their abundance pattern along different seasons, helped considerably in understanding the similarity in their distribution in the estuary. During the pre-monsoon season, the three species that formed the dominant as well 
as the characterizing species were found in a single cluster, and most of the other characterizing species were found in another cluster (Fig. 6a). During the monsoon season, all the dominant and characterizing species were found in a single large cluster (Fig. 6b). During the postmonsoon season, the two dominant species (A. plumosa and $B$. similis) were found in a separate cluster, whereas most of the characterizing species were observed in a large cluster. The characterizing species that had preferences for a low-salinity environment (Pseudodiaptomus malayalus, Ac. gravelyi, and Ac. keralensis) were also found in a separate cluster (Fig. 6c).

Figure 7 a describes the similarity in the station locations along different seasons derived through the NMDS analysis, based on the Bray-Curtis similarity indices, using the abundance of different copepod species present along each season. The variability of the spatial abundance of the two common dominant as well as characterizing species of each season (A. plumosa, B. similis), overlaid on the MDS plot, also indicated their affinity towards the mediumsalinity environment during each season (Fig. 7b, c).

\section{Diversity indices}

Species diversity $\left(H^{\prime}\right)$ of the copepods varied both spatially and temporally (Fig. 8a). As the inlet locations are relatively more influenced by the nearby marine environment compared to the other locations, the seasonal scenario of $H^{\prime}$ was checked separately for the inlet and the non-inlet locations and also for all the station locations together. In both cases, though copepod abundance was higher during the pre-monsoon season, $H^{\prime}$ was higher during the postmonsoon period. Species evenness $\left(J^{\prime}\right)$ did not show much variation with the seasons $(0.6 \pm 0.1,0.6 \pm 0.2$, and $0.5 \pm 0.1$ for the pre-monsoon, monsoon, and post-monsoon seasons, respectively) (Fig. $8 \mathrm{~b}$ ). The maximum evenness value was observed at station 8 (0.9) during the monsoon season.

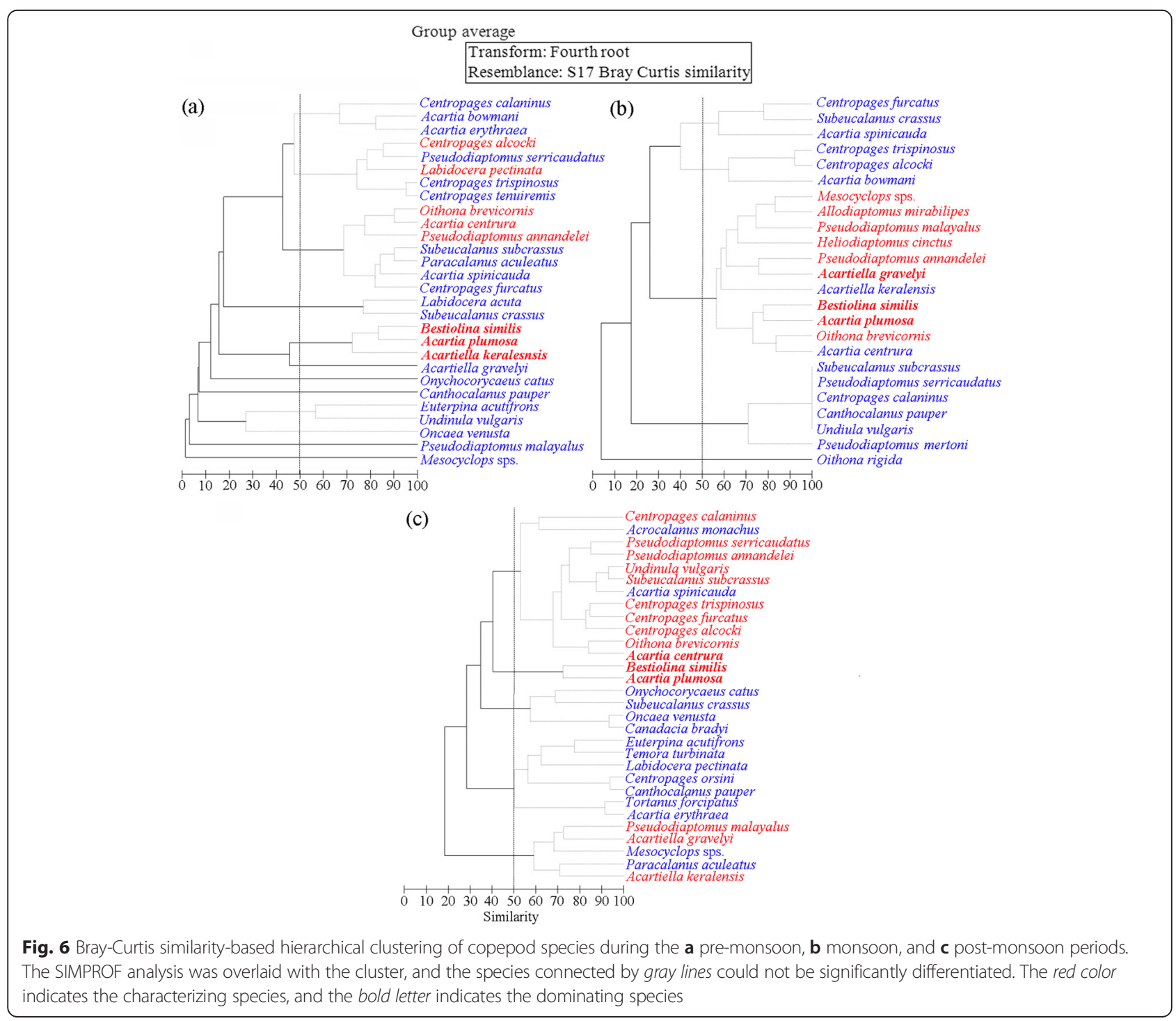




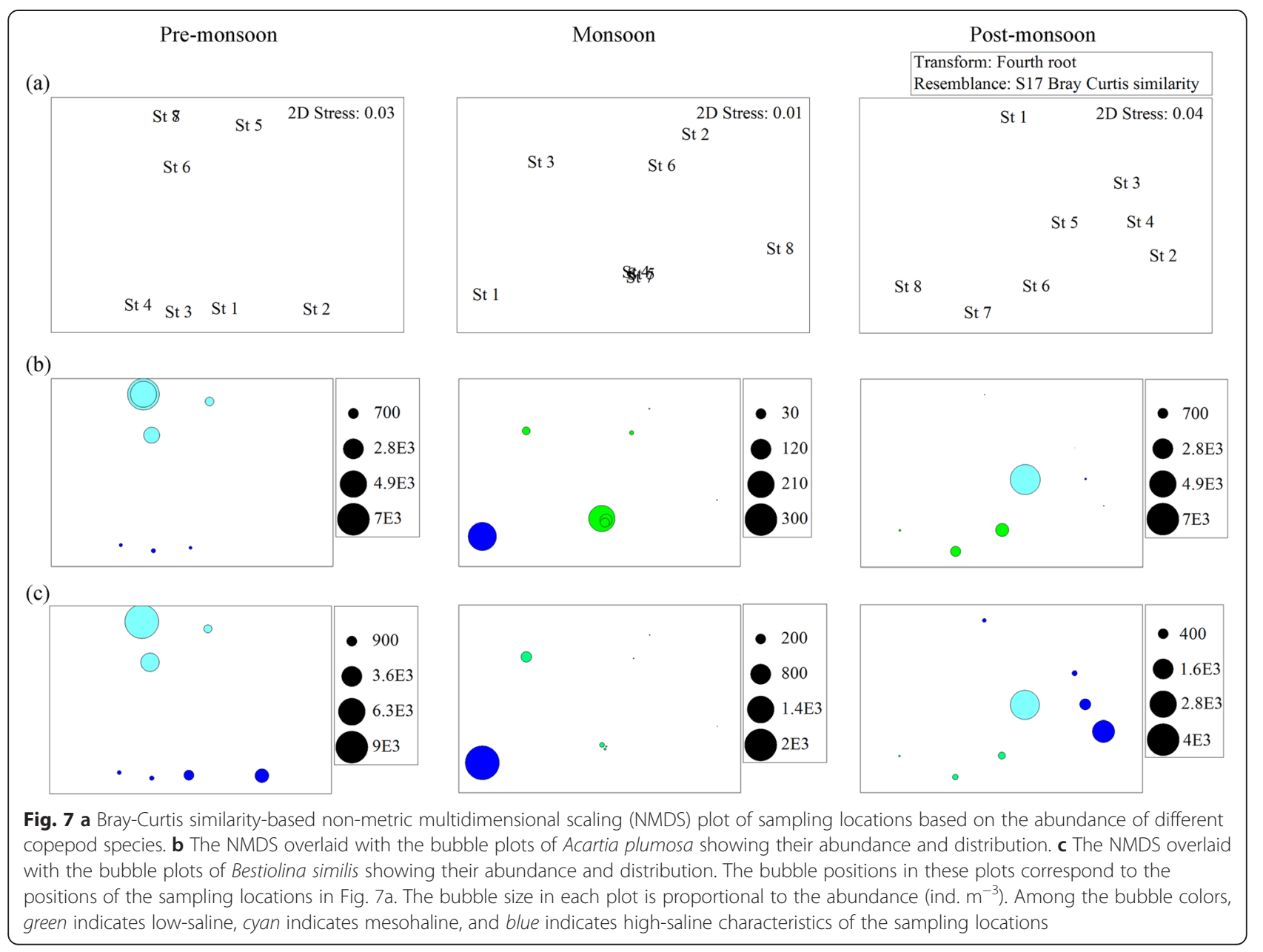

\section{Sex ratio and abundance pattern}

Since A. plumosa and B. similis were found as the only two species that remained the dominant as well as characterizing species during all three seasons, a detailed investigation of their sex ratio was carried out to understand whether sex-specific differences had any determining role in the maintenance of their population in the estuarine system. In the case of both A. plumosa and $B$. similis, the seasonal scenario revealed relatively higher sex ratio values during the monsoon season and lower values during the pre-monsoon period (Fig. 9). A prominent skewness towards female dominance was evident in the sex ratio of both the species, and in A. plumosa, it varied between 0.02 and 0.98 (av. $0.36 \pm 0.2$ ). Except for one higher value (1.99) during the monsoon season, the sex ratio of $B$. similis was also limited between 0.05 and 0.8 (av. $0.31 \pm 0.26$ ). The interrelation between sex ratio and the abundance of $A$. plumosa showed a significant negative relation $(P<0.05)$ during both the premonsoon and monsoon periods, whereas during the post-monsoon season, it did not show any particular trend $(P>0.05)$ (Fig. 10a). The result of the one-sample $t$ test also showed that the regression lines are significantly different from zero during the pre-monsoon and monsoon periods (Fig. 10a). The analysis carried between the residuals extracted from the regression plot of A. plumosa and the freshwater content did not show any significant relationship $(P>0.05)$ in any season (Fig. 10b). $B$. similis exhibited a negative relation with abundance in all three seasons, and it was significant during the pre-monsoon and post-monsoon periods $(P<0.05)$ (Fig. 10c), indicating an influence of the biased sex ratio in the variability of their abundance. In case of B. similis, the result of the one-sample $t$ test revealed that the regression lines are significantly different from zero during the pre-monsoon and post-monsoon periods (Fig. 10c) but the interrelation between the residuals extracted from the regression plot and the freshwater content showed a significant negative relation $(P<0.05)$ only during the monsoon period (Fig. 10d).

\section{Discussion}

While assessing the seasonal variability of the abiotic parameters and their control on copepod dynamics, the 

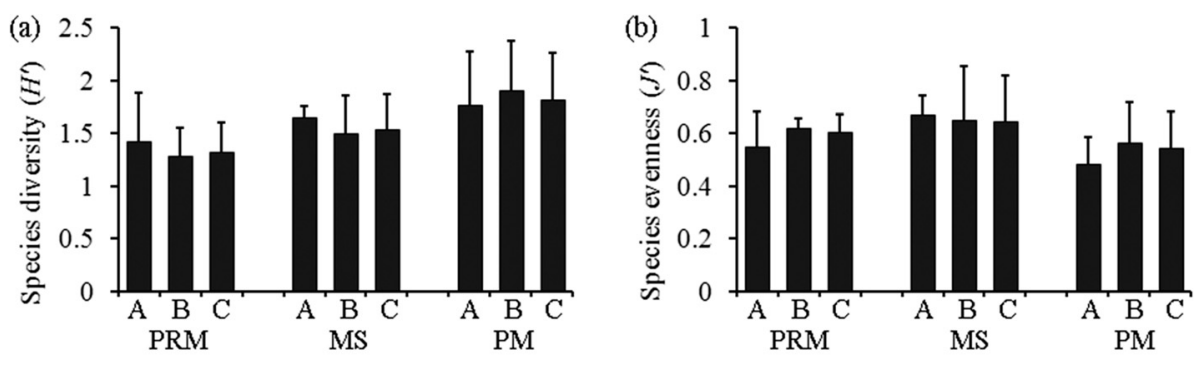

A - Inlet stations B - Non-inlet stations C - All stations together

Fig. 8 Diversity indices a species diversity and $\mathbf{b}$ species evenness, along the three seasons. The vertical line on the bar diagram indicates the standard deviation. PRM pre-monsoon, MS monsoon, PM post-monsoon)

spatial scale gradients in the biotic and abiotic variables and their subsequent effects on the estuarine ecology were also given importance for a better elucidation of the spatio-temporal heterogeneity occurring in the zooplankton community of this dynamic estuarine system. Marked seasonality and unsteadiness in the salinity values, regulated by the monsoonal rainfall, were prominent in the system, supporting its categorization as a typical monsoonal estuary. During the monsoon season, due to the heavy rainfall $(\sim 300 \mathrm{~cm})$ and associated high river influx, the entire estuarine system behaved as a limnetic region with low-salinity values. Revichandran et al. (2012) have shown that in the CE, nearly $60 \%$ of the total annual rainfall occurs during the summer monsoon period, and this, along with the subsequent river runoff (60-70\% of the total), contributes greatly in the conversion of the estuary into a freshwater-dominated region. Therefore, a marked salinity range $(0.1-28.5)$ prevailed between the upper and lower reaches of the estuary, and the salinity value could not reach $>5$, except at one inlet location. With the post-monsoon season, due to the gradual intrusion of the Arabian Sea water (Menon et al. 2000), though the salinity of the entire study area progressively increased, a salinity gradient prevailed between the upper and lower reaches, with a mesohaline zone in the middle reaches. During the premonsoon season, with markedly less river influx (1.69\%, Srinivas et al. 2003) and high incursion of the Arabian
Sea water, the stations located at the lower reaches of the CE behaved as an extended part of the Arabian Sea (Madhupratap 1987). The low-salinity gradient (20.1 \pm 6.4) during this period was the result of the progression of high-salinity water up to the middle reaches of the estuary, resulting in the development of a mesohaline zone in the upstream locations of the estuary (stations (St.) 6-8). The limited seasonal variation in the temperature distribution throughout the estuary might be due to its tropical nature, whereas the less conspicuous seasonal variation in the DO could be due to the existence of higher phytoplankton standing stock, irrespective of the season (Madhu et al. 2007). The significant seasonal variation observed in the $\mathrm{pH}$ distribution might have happened by the difference occurring in the seasonal fluvial runoff characteristics and saline water intrusion (Saraladevi et al. 1983).

The higher zooplankton abundance observed during the pre-monsoon season and the lower abundance during the monsoon season, in accordance with the average seasonal salinity pattern of the estuarine system, generally put forth the question of whether an increase in the salinity always leads to higher zooplankton abundance. The earlier studies depicting the zooplankton distribution, based on the average seasonal salinity and abundance values, support the concept of salinityinfluenced zooplankton abundance (Rao et al. 1975; Jyothibabu et al. 2006; Madhu et al. 2007) in the CE.
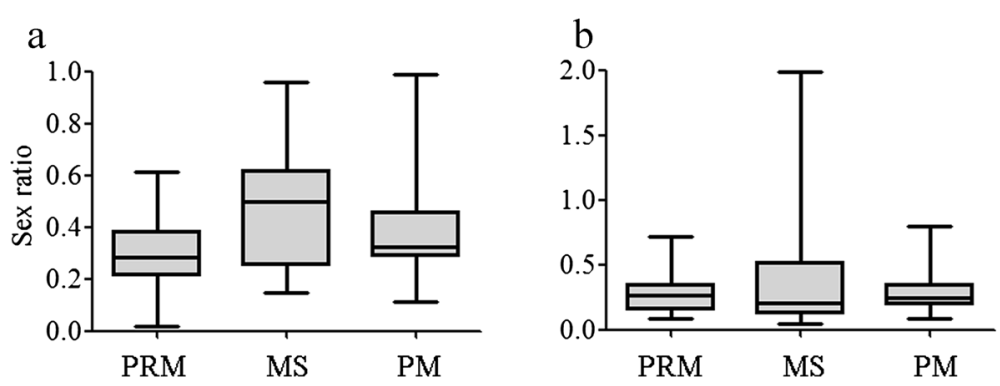

Fig. 9 The seasonal variability of the sex ratio of the dominant species a Acartia plumosa and $\mathbf{b}$ Bestiolina similis 


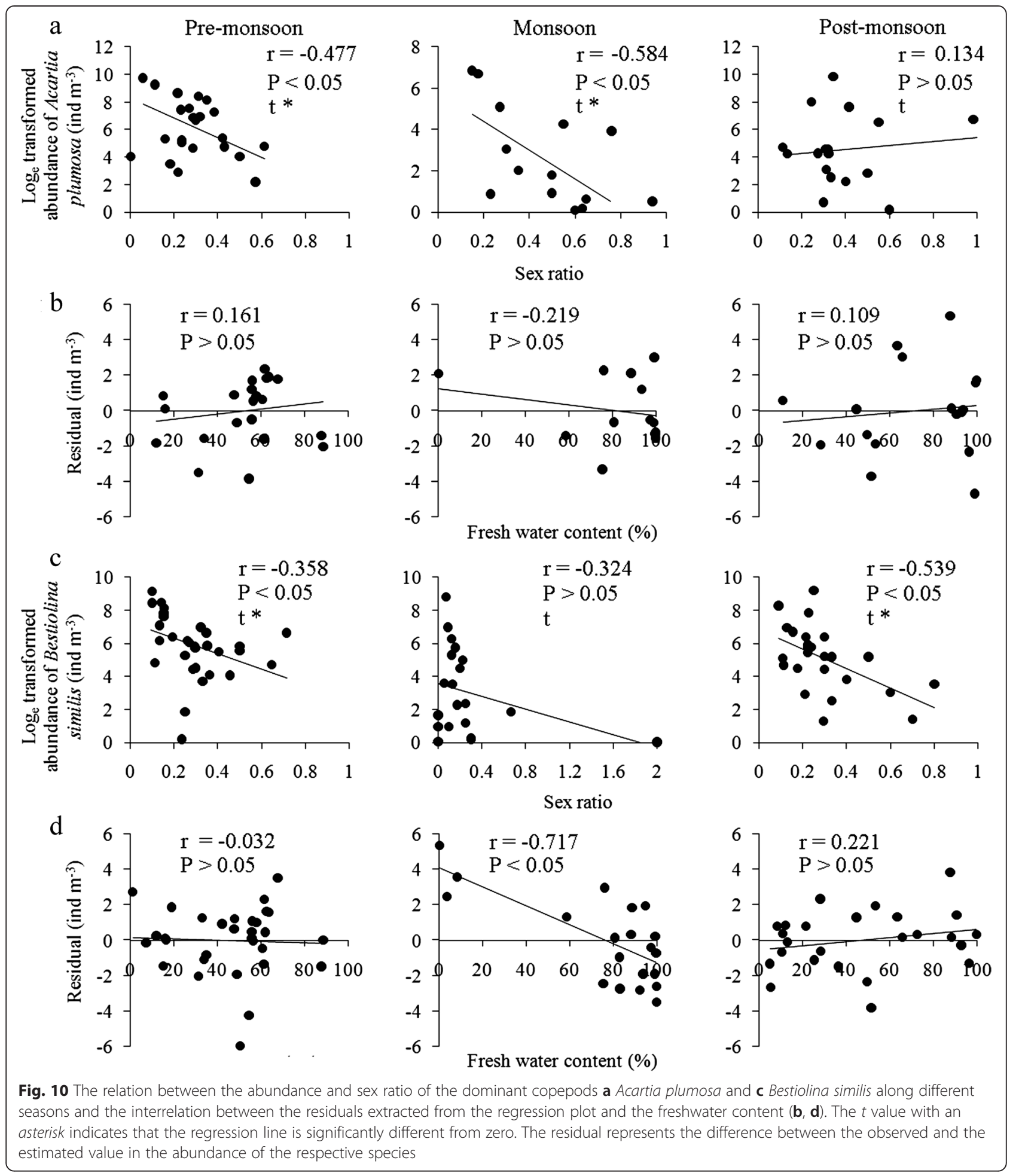

However, the detailed spatio-temporal analysis during the present study evidenced a varied view in the interrelation between salinity and the zooplankton community in this monsoonal estuary. During the premonsoon season, though a high-salinity environment (salinity >18) prevailed in the lower reaches of the estuarine zone, higher zooplankton abundance was observed, mostly at the mesohaline zones (salinity 5-18) at the upstream locations, which indicates a positive affinity of the estuarine organisms towards the mesohaline salinity ranges. During the monsoon season, among all the sampling locations in the CE, only the inlet 
location, station 1 , had salinity $>5$, and concurrently, higher zooplankton abundance was observed at that station. The higher abundance of zooplankton, mainly at the mesohaline zone of the estuary, during the postmonsoon period also (Figs. 2 and 3) further validates our concept of the preference of mesohaline salinity ranges by the estuarine zooplankton community compared to the very high-salinity environments or very low-salinity environments. Though the result of our study differs from the observation of Kimmerer et al. (1998) on the distribution of a major population of estuarine zooplankton in the low-salinity zone of the temperate San Francisco estuary, the findings of Cronin et al. (1962) in the Delaware estuary clearly support our view of the affinity of estuarine organisms towards the mesohaline zone.

Since copepods formed the predominant zooplankton taxon, contributing $>87 \%$ of the total abundance, and are in accordance with earlier observations (Madhupratap 1987; Madhu et al. 2007), the present study, depicting the detailed spatio-temporal distribution, community composition, and species-specific abundance pattern, helped considerably in a better understanding of the ecology of the zooplankton community of this estuarine system. Irrespective of the season, the higher preponderances of the copepod community in the mesohaline zones of the estuary clearly validate their affinity towards the mesohaline environment. With the evident intense seasonality in the abiotic variables and in copepod abundance, a prominent change is also expected in the copepod community structure and in the relative contribution of different species towards the total copepod population. But, the higher contribution of the mesohaline species $A$. plumosa and B. similis, a euryhaline opportunistic colonizing paracalanoid, towards the higher abundance in the mesohaline zones of the CE, irrespective of season, points towards a significant role they play in the sustenance of the copepod community in this estuarine system. Prior reports on the higher abundance of $B$. similis and $A$. plumosa in different tropical estuaries along the Indian coast (Goswami 1982; Ramaiah et al. 1996; Dalal and Goswami 2001) are in agreement with our findings in the CE. The predominantly omnivorous diet of both these copepod species, along with their short generation time of 7-10 days (VanderLugt and Lenz 2009), might have favored their contribution towards higher abundance in the mesohaline zones of the estuarine region. Hence, the observation of the higher abundance and dominance of these copepods and their preferences for the mesohaline zones of the estuary throughout the study period further substantiate the concept of considering them the most suitable estuarine endemic among the copepod community for this tropical monsoonal estuary. The evident pattern of distribution and abundance of the copepods $P$. annandalei and O. brevicornis as the characterizing species of all three seasons, along with A. plumosa and B. similis, suggest their supporting role in the sustenance of the estuarine copepod community. Hence, the view on the vital role of the allochthonous population in the maintenance of the estuarine zooplankton abundance compared to the autochthonous populations, as observed in the temperate EMS estuary by Baretta and Malschaert (Baretta and Malschaert 1988), seems inapplicable in the case of this typical tropical monsoonal estuarine system.

The interrelation between the copepod species abundance and the distribution, based on their preferred environment, was examined in detail to have a better understanding on the determining role of the estuarine characteristics on the population dynamics and also on the complexities in relation between copepod species and the seasonal salinity patterns. As observed in the triplot of the RDA, during the pre-monsoon season, when a major part of the estuary behaves as an extension of the neighboring Arabian Sea due to the high marine water incursion (Madhupratap 1987; Srinivas et al. 2003), A. plumosa and B. similis showed negative affinity with salinity, and in contrast, during the monsoon season, when the estuary gets transformed as a freshwaterdominated system due to the higher precipitation and fluvial runoff, their abundance exhibited positive affinity with salinity, whereas in the transitional phase during the post-monsoon season, no particular trend was found, further affirming their preferences towards the mesohaline environment. Among the characterizing species, the observed negative affinity of the low-saline species $A$. gravelyi, $P$. malayalus, and $\mathrm{Al}$. mirabilipes and the positive affinity of the high-saline species Undinula vulgaris, S. subcrassus, A. centrura, Pseudodiaptomus serricaudatus, Centropages calaninus, and Centropages furcatus towards salinity along different seasons truly characterize their preferences for the specific saline zones in the estuarine system. Similar observations on salinity-specific habitat preferences have been reported in the zooplankton community of temperate estuaries also (Collins and Williams 1981) as the occurrence in the habitat of preferred salinity ranges aids in the higher survival rate and also boosts their toleration capacity (Lance 1963). Among the copepod species, the assemblages observed among the dominant and characterizing species of the copepod (Fig. 6) further point towards their similarity in habitat preferences. The unique seasonal copepod community structure in the $\mathrm{CE}$ might have been regulated by the distinct species-specific salinity preferences and tolerance of the copepod population to the variability in the abiotic factors generated by the estuarine seasonality. Among these species, the ones with more affinity and 
adaptability to the seasonal estuarine characteristics might have gotten an advantage to be the dominant and characterizing species of the respective season.

Though in CE relatively low copepod diversity $\left(H^{\prime}<2\right)$ was observed across the seasons, the seasonal variability in the $H^{\prime}$ value observed during the study period helped further in a better understanding of the variability occurring in the seasonal composition of the copepod community. The low species diversity of copepods during the monsoon period might have resulted due to the absence of high-saline marine migrants with a salinity preference $>20$, and a similar feature has also been observed in other monsoonal estuarine systems along the Indian coast (Goswami 1982) and also in the coastal waters of this region (Stephen 1977). The interesting feature evident in the seasonal diversity and abundance pattern with high abundance during the pre-monsoon season and high $H^{\prime}$ during the postmonsoon season augmented the need to understand the role of community composition during periods of varying abundance and diversity. During the post-monsoon season, though salinity progressively increased, a wide salinity range prevailed in the estuary (salinity-St. 1-4>18, St. $5>5$ and $<18$, and St. 6,7 , and $8,<5$ ), which in turn triggered different copepod species to inhabit niches of preferred salinity ranges in the estuary with maximum abundance at the mesohaline middle reaches. This was evident from the restricted occurrence of the low-saline copepod species $P$. malayalus and $H$. cinctus (salinity preference $<10$ ) in the southern limb of the estuary and several high-saline species (salinity preference $>20$ ) in the polyhaline region (salinity $>18$ ) in or near the two inlets. Most of the medium-saline species had wide distributions in the estuary, based on their specific salinity preferences. In contrast, during the pre-monsoon season, though the abundance was higher, it was mostly contributed by the mesohaline and euryhaline copepods, with maximum abundance in the mesohaline upstream locations. Though several high-saline species were present in varying abundance during this period, the species that had preferences to low salinity were mostly absent in the estuarine zone, resulting in the lower $H^{\prime}$ during this period.

As a fundamental trait of the sexually reproducing population, studies on the sex ratio, its variability from the Fischerian 1:1 ratio in the natural population, and the factors responsible for the skewness have received attention from the scientific community (Gusmão et al. 2013). Both laboratory studies (Irigoien et al. 2000; Dur et al. 2012) as well as field observations (Moraitou-Apostolopaulou 1972) imply the role of variability of sex ratio in governing the population dynamics of the copepod community, and hence, in the present study, it became an important tool to unfold the critical role they play in sustaining the population of the two dominant copepod species, A. plumosa and $B$. similis, in this dynamic estuarine ecosystem. In the seasonal scenario, the observation of the lower sex ratio during the period of higher abundance and vice versa clearly indicates the leaning of sex ratio towards female dominance during higher abundance. This observation of skewness in sex ratio towards females, in conjunction with the abundance pattern, is against the view of MoraitouApostolopaulou (1972) in the temperate Aegean Sea but is in agreement with the observations made by Saraswathy and Santhakumari (1982) on the copepod population along the coastal waters of India. The incident high female skewness in the copepod population might be an advantage towards easier mate finding for the male copepods and in turn facilitates higher reproductive output during the stable (with the lowest riverine influx) and food-rich environment (maximum chlorophyll $a$ ) in the premonsoon period, leading to the higher abundance. In the $\mathrm{CE}$, the abundance of microzooplankton, another major diet of the copepod (Calbet and Saiz 2005), has also been recorded at maximum levels during the pre-monsoon period (Jyothibabu et al. 2006). Hence, along with higher chlorophyll $a$, this might also have played a role in supporting the biased sex ratio and, in turn, the higher abundance of the dominant omnivorous copepod species, $A$. plumosa and B. similis, during the pre-monsoon season. As the female copepods have comparatively higher feeding efficiency and are reported to be voracious feeders than their male counter parts, they might have utilized the food-rich environment more efficiently than the males, resulting in their dominance. The negative relation observed between the abundance and the sex ratio of both copepod species during most of the seasons (Fig. 10) further supports the inclination towards female skewness during the period of higher abundance. The insignificant relation observed between the freshwater content and the residuals extracted from the regression plots of both species also clearly substantiates the role of sex ratio in their abundance. The preference for mesohaline environment over the low- and high-saline environments might be the reason for the insignificant relation observed between the freshwater content and the residuals extracted from the regression plots (Fig. 10). The interrelation between the dominant and characterizing species of the copepod and phytoplankton community further helped to understand the influence that the autotrophic community has on the sex ratio-abundance pattern of the dominant copepod species. Irrespective of the season, A. plumosa and B. similis, which remained dominant throughout the study period, exhibited a preference for the autotrophic dinoflagellate species than the diatoms (Fig. 5). Compared to the diatoms, the dinoflagellates have been reported to have potential influence on egg production, hatching viability, and, in turn, the reproductive success of copepod species (Ceballos and Ianora 2003), as they provide more protein, carbohydrate, and lipid than diatoms of equivalent volume 
(Kleppel 1993). Thus, the female-biased sex ratio and the feeding preference towards dinoflagellates over diatoms of both dominant estuarine endemic copepod species (Fig. 5) might have helped them in maintaining the dominance and also in their population sustenance during each season.

The NMDS plot expressing the similarity between stations along different seasons, based on the abundance of all copepod species, and addressing the variability in the spatial abundance of the two dominant species further helped us to get a better inference of their spatio-temporal distribution. The distinct groups of the station locations, based on the abundance of different copepod species, showed a close affinity towards the different salinity ranges, signifying the role of salinity in their abundance and distribution (Fig. 7a). The higher abundance of both A. plumosa and $B$. similis in the mesohaline region (Fig. $7 \mathrm{~b}, \mathrm{c}$ ) and the negative relation of sex ratio with their abundance values (Fig. 10) indicate towards the role of sex ratio in maintaining their high population in the mesohaline environment of the estuary.

\section{Conclusions}

The evident heterogeneity in the spatial and temporal abundance, community composition, and diversity indices of the copepod community in the $\mathrm{CE}$ is governed mainly by the species-specific sensitivity and subsequent responses of the organisms towards the prime limiting abiotic variable, salinity. In spite of the prominent unsteadiness in the salinity characteristics induced by the seasonal variability in the precipitation regime and fluvial fluxes influenced by the Indian summer monsoon (Revichandran et al. 2012), the maximum zooplankton abundance always occurred at the mesohaline zone of the estuary, which experienced a seasonal shift from the lower reaches of the estuary during the monsoon season to the middle reaches during the post-monsoon season and ultimately towards the upstream locations of the estuary during the pre-monsoon period, in contrast to the expected high-salinity zones of the estuary. The dominant zooplankton taxon, copepods (>87 \%), played a crucial role in the maintenance of the higher abundance of the zooplankton community in the mesohaline zones of the estuary. Depending on the seasonal variability in salinity, though a few high-saline and low-saline species flourished in the lower and upper reaches of the estuary, respectively, the estuarine copepod community was dominated by the preponderance of the mesohaline and euryhaline copepods $A$. plumosa and B. similis, along with $O$. brevicornis and P. annandalei, as the characterizing species, irrespective of the season. The role of sex ratio in the maintenance of the higher abundance of the dominant estuarine endemic species in the mesohaline region was another important finding in the present study, and in the seasonal scenario, the bias in the sex ratio towards female skewness might have favored higher reproductive output, resulting in the higher abundance during the favorable pre-monsoon period. Hence, the species-specific sensitivity to the seasonal changes in the salinity distribution of the copepod community played a prominent role in determining their abundance pattern in the $\mathrm{CE}$, and the trend in the sex ratio of the dominant copepods towards female dominance further aided in sustaining the higher abundances in the mesohaline zone. Considering the limited study on tropical monsoonal estuarine zooplankton dynamics, the results of the present study will be relevant in the better understanding of the unique population sustenance of the estuarine endemic zooplankton community. Further studies can be focused towards understanding the mechanisms that lead to the biasness in the sex ratio of the estuarine endemic copepod species.

\section{Additional file}

Additional file 1: List of the dominant and characterizing species of phytoplankton along different seasons in the Cochin estuary.

\#-dominant species, *-characterizing species. (DOCX 14 kb)

\section{Competing interests}

The authors declare that they have no competing interests.

\section{Authors' contributions}

VG and NVM designed the study. VG analyzed the sample. VG, NVM, and KKK analyzed and interpreted the data. All four authors helped in drafting the manuscript. All authors read and approved the final manuscript.

\section{Acknowledgements}

We express our sincere gratitude to the Director, CSIR-National Institute of Oceanography, for the facilities provided. This work forms a part of the Supra Institutional Project-1302 - "Eco biogeography of the estuarine and coastal waters of south-west coast of India," of NIO. We thank all the scholars of the project SIP 1302 for their help rendered during sampling. We also convey our sincere thanks to both the anonymous reviewers for their valuable suggestions to improve the manuscript. The first author acknowledges Dr. M. Rakhesh, University of Bergen, Norway, and Dr. K.V. Jayalakshmi, CSIR-NIO, for the constructive suggestions which helped to improve the manuscript. The first author is also thankful to CSIR, New Delhi for the Senior Research Fellowship. This is NIO contribution number 5777.

Received: 30 July 2014 Accepted: 2 July 2015

Published online: 30 July 2015

\section{References}

Alongi DM (1998) Coastal ecosystem processes. CRC Press, Boca Raton, Florida APHA (2005) Standard methods for the examination of water and wastewater, 21st edn. American Public Health Association/American Water Works Association / Water Environment Federation, Washington DC

Baretta JW, Malschaert JFP (1988) Distribution and abundance of the zooplankton of the EMS estuary (North Sea). Neth J Sea Res 22:69-81

Calbet A, Saiz E (2005) The ciliate-copepod link in marine ecosystems. Aquat Microb Ecol 38:157-167

Ceballos S, lanora A (2003) Different diatoms induce contrasting effects on the reproductive success of the copepod Temora stylifera. J Exp Mar Biol Ecol 294:189-202

Clarke KR, Gorley RN (2006) PRIMER v6: user manual/tutorial. PRIMER-E, Plymouth Clarke KR, Warwick RM (2001) Change in marine communities: an approach to statistical analysis and interpretation, 2nd edn. PRIMER-E, Plymouth 
Collins NR, Williams R (1981) Zooplankton of the Bristol Channel and Severn estuary. The distribution of four copepods in relation to salinity. Mar Biol 64:273-283

Cronin LE, Daiber JC, Hulbert EM (1962) Quantitative seasonal aspects of zooplankton in the Delaware River estuary. Chesapeake Sci 3:63-93

Dalal SG, Goswami SC (2001) Temporal and ephemeral variations in copepod community in the estuaries of Mandovi and Zuari-west coast of India. J Plankton Res 23:19-26

Dur G, Souissi S, Schmitt FG, Cheng SH, Hwang JS (2012) Sex ratio and mating behaviour in the calanoid copepod Pseudodiaptomus annandalei. Zool Stud 51:589-597

Fisher TR, Carlson PR, Barber RT (1982) Sediment nutrient regeneration in three North Carolina estuaries. Estuar Coast Shelf Sci 14:101-116

Froneman PW (2004) Zooplankton community structure and biomass in a southern African temporarily open/closed estuary. Estuar Coast Shelf Sci 60:125-132

Goswami SC (1982) Distribution and diversity of copepods in the Mandovi-Zuari estuarine system, Goa. Indian J Mar Sci 11:292-295

Grasshoff K (1983) Determination of oxygen. In: Grasshoff K, Ehrhardt M, Kremling K (eds) Methods of sea water analysis. Verlag Chemie, Weinheim, pp 61-72

Gupta GVM, Thottathil SD, Balachandran KK, Madhu NV, Madeswaran P, Nair S (2009) $\mathrm{CO}_{2}$ supersaturation and net heterotrophy in a tropical estuary (Cochin, India): influence of anthropogenic effect. Ecosystems 12:1145-1157

Gusmão LFM, McKinnon AD, Richardson AJ (2013) No evidence of predation causing female-biased sex ratios in marine pelagic copepods. Mar Ecol Prog Ser 482:279-298

Haedrich R (1983) Estuarine fishes. In: Ketchum BH (ed) Estuaries and enclosed seas. Elsevier, Amsterdam, pp 183-208

Harris R, Wiebe P, Lenz J, Skjoldal HR, Huntley ME (eds) (2000) ICES zooplankton methodology manual. Academic Press, London

Hirst AG, Bonnet D, Conway DVP, Kiørboe T (2010) Does predation control adult sex ratios and longevities in marine pelagic copepods? Limnol Oceanogr 55:2193-2206

Irigoien X, Obermüller B, Head RN, Harris RP, Rey C, Hansen BW, Hygum BH, Heath MR, Durbin EG (2000) The effect of food on the determination of sex ratio in Calanus spp.: evidence from experimental studies and field data. ICES J Mar Sci 57:1752-1763

Jyothibabu R, Madhu NV, Jayalakshmi KV, Balachandran KK, Shiyas CA, Martin GD, Nair KKC (2006) Impact of fresh water influx on micro zooplankton mediated food web in a tropical estuary (Cochin backwaters), India. Estuar Coast Shelf Sci 69:505-515

Kasturirangan LR (1963) A key for the identification of the more common planktonic copepod of Indian coastal waters. INCOR (CSIR), New Delhi

Kimmerer WJ (2002) Physical, biological, and management responses to variable freshwater flow into the San Francisco estuary. Estuaries 25:1275-1290

Kimmerer WJ, Burau JR, Bennett WA (1998) Tidally oriented vertical migration and position maintenance of zooplankton in a temperate estuary. Limnol Oceanogr 43:1697-1709

Kinne O (1966) Physiological aspects of animal life in estuaries with special reference to salinity. Netherlands J Sea Res 3:222-244

Kleppel GS (1993) On the diets of calanoid copepods. Mar Ecol Prog Ser 99:183-195

Lance J (1963) The salinity tolerance of some estuarine planktonic copepods. Limnol Oceanogr 8:440-449

Laprise R, Dodson JJ (1994) Environmental variability as a factor controlling spatial patterns in distribution and species diversity of zooplankton in the St. Lawrence Estuary. Mar Ecol Prog Ser 107:67-81

Lee CY, Liu DC, Su WC (2009) Seasonal and spatial variations in the planktonic copepod community of Ilan Bay and adjacent Kuroshio waters off northeastern Taiwan. Zool Stud 48:151-161

Madhu NV, Jyothibabu R, Balachandran KK, Honey UK, Martin GD, Vijay JG, Shiyas CA, Gupta GVM, Achuthankutty CT (2007) Monsoonal impact on planktonic standing stock and abundance in a tropical estuary (Cochin Backwaters-India). Estuar Coast Shelf Sci 73:54-64

Madhupratap M (1987) Status and strategy of zooplankton of tropical Indian estuaries: a review. Bull Plankton Soc Japan 34:65-81

Menon NN, Balchand AN, Menon NR (2000) Hydrobiology of the Cochin backwater system—a review. Hydrobiologia 430:149-183

Moraitou-Apostolopaulou M (1972) Sex ratio in the pelagic copepods, Temora stylifera Dana and Centropages typicus Kroyer. J Exp Mar Biol Ecol 8:83-87
Ohman MD, Hsieh CH (2008) Spatial differences in mortality of Calanus pacificus within the California current system. J Plankton Res 30:359-366

Qasim SZ (2003) Indian estuaries. Allied Publication, Mumbai

Ramaiah N, Chatterji A, Madhupratap M (1996) A study on the zooplankton of the Burhabalanga estuary, Orissa coast. Proc Indian Natn Sci Acad B62:1-4

Rao TSS, Madhupratap M, Haridas P (1975) Distribution of zooplankton in space and time in a tropical estuary. Bull Dept Mar Sci Univ Cochin 7:695-704

Revichandran C, Srinivas K, Muraleedharan KR, Rafeeq M, Shivaprasad A, Vijayakumar K, Jayalakshmy KV (2012) Environmental set-up and tidal propagation in a tropical estuary with dual connection to the sea (SW coast of India). Environ Earth Sci 66:1031-1042

Rodríguez-Graña L, Calliari D, Tiselius P, Hansen BW, Sköld HN (2010) Gender-specific ageing and non-Mendelian inheritance of oxidative damage in marine copepods. Mar Ecol Prog Ser 401:1-13

Saraladevi K, Venugopal P, Remani KN, Zacharias D, Unnithan RV (1983) Nutrients in some estuaries of Kerala. Mahasagar 16:161-173

Saraswathy M, Santhakumari V (1982) Sex ratio of five species of pelagic copepods from Indian Ocean. Mahasagar 15:37-42

Sewell RBS (1999) The copepod of Indian seas. Daya Books, India

Smith SV, Hollibaugh JT (1993) Coastal metabolism and the oceanic organic carbon balance. Rev Geophys 31:75-89

Soetaert K, Rijswijk PV (1993) Spatial and temporal pattern of the zooplankton in the Westerschelde estuary. Mar Ecol Prog Ser 97:47-59

Srinivas K, Revichandran C, Maheswaran PA, Mohamed ATT, Murukesh N (2003) Propagation of tides in the Cochin estuarine system, southwest coast of India. Indian J Mar Sci 32:14-24

Stephen R (1977) Calanoid copepods from the shelf and slope waters off Cochin: distribution, biomass and species diversity, Proc Symp Warmwater Zooplankton. Unesco/NIO 21-27

Strickland JDH, Parsons TR (1972) A practical handbook of seawater analysis. Bulletin of Fisheries Research Board, Canada

Tomas CR (1997) Identifying marine phytoplankton. Academic, USA

Van den Wollenberg AL (1977) Redundancy analysis. An alternative for canonica correlation analysis. Psychometrika 42:207-219

VanderLugt K, Lenz PH (2009) Handbook for the Cultivation of two Hawaiian paracalanid copepods. University of Hawaii, Honolulu

Vijith V, Sundar D, Shetye SR (2009) Time-dependence of salinity in monsoonal estuaries. Estuar Coast Shelf Sci 85:601-608

Wellershaus S (1969) On the taxonomy of planktonic copepod in the Cochin backwater (a south Indian estuary). Veröff Inst Meeresforsch Bremerh 11:245-286

Yang GM, He DH, Wang CS, Miao YT, Yu HH (1999) Study on the biological oceanography characteristics of planktonic copepods in the waters north of Taiwan, II. Community characteristics. Acta Oceanol Sin 21:72-80

\section{Submit your manuscript to a SpringerOpen ${ }^{\odot}$ journal and benefit from:}

- Convenient online submission

- Rigorous peer review

- Immediate publication on acceptance

- Open access: articles freely available online

- High visibility within the field

- Retaining the copyright to your article

Submit your next manuscript at springeropen.com 